\title{
1 Fidelity to foraging sites after long migrations
}

2

3 Takahiro Shimada ${ }^{1,2}$, Colin J. Limpus ${ }^{3}$, Mark Hamann ${ }^{1}$, Ian Bell ${ }^{3}$, Nicole Esteban ${ }^{4}$, Rachel

4 Groom $^{5}$, Graeme C. Hays 6

5

$6 \quad{ }^{1}$ College of Science and Engineering, James Cook University, Townsville, Queensland, Australia

$7 \quad{ }^{2}$ Australian Institute of Marine Science, Crawley, Western Australia, Australia

$8 \quad{ }^{3}$ Department of Environment and Science, Queensland, Australia

$9{ }^{4}$ Department of Biosciences, Swansea University, Singleton Park, Swansea, Wales, SA2 8PP, 10 UK

11 5epartment of Environment and Natural Resources, Palmerston, Northern Territory, Australia

$12{ }^{6}$ Deakin University, Geelong, Victoria, Australia

13

14 Correspondence: t.shimada@aims.gov.au

16 Keywords: risk taking, biologging, Fastloc GPS, Argos, Chelonia mydas, Caretta caretta, 17 Eretmochelys imbricata, Natator depressus. 


\section{Abstract}

19 1. Patterns of animal movement associated with foraging lie at the heart of many ecological

20 studies and often animals face decisions of staying in an environment they know, versus

21 relocating to new sites.

22 2. The lack of knowledge of new foraging sites means there is risk associated with a decision to

23 relocate (e.g. poor foraging) as well as a potential benefit (e.g. improved foraging).

24 3. Using a unique long-term satellite tracking dataset for several sea turtle species, combined

25 with capture-mark-recapture (CMR) data extending over 50 years, we show how, across species,

26 individuals generally maintain tight fidelity to specific foraging sites after extended (up to almost

$2710,000 \mathrm{~km}$ ) migration to and from distant breeding sites as well as across many decades.

28 4. Migrating individuals often travelled through suitable foraging areas en route to their "home"

29 site and so extended their journeys to maintain foraging site fidelity.

30 5. We explore the likely mechanistic underpinnings of this trait, which is also seen in some

31 migrating birds, and suggest that individuals will forgo areas of suitable forage encountered en

32 route during migration when they have poor knowledge of the long-term suitability of those

33 sites, making relocation to those sites risky. 


\section{1 | INTRODUCTION}

Migration is an integral component of the life history of many animals with a range of examples of birds, mammals, fish, insects, and reptiles that migrate up to many $1000 \mathrm{~s}$ of $\mathrm{km}$. The oft cited general reason for migration is that the quality of resources, such as food availability, varies through space and time, so that it is best for an animal to visit particular locations at specific times (e.g. Alerstam, Hedenström, \& Åkesson, 2003). In some cases the end point of migration is associated with tight fidelity to particular sites. For example, many taxa including birds, sea turtles and some fish migrate to specific breeding sites to which they maintain fidelity across years (Bett \& Hinch, 2016; Jensen, FitzSimmons, \& Dutton, 2013; Vardanis, Nilsson, Klaassen, Strandberg, \& Alerstam, 2016). This fidelity may help ensure that individuals breed in suitable sites. Likewise there may be fidelity to foraging sites with for example, many wading birds breeding in northern Europe travelling 1000s of km to West Africa to forage in winter in particular wetland areas, notably Banc d'Arguin which covers approximately $12,000 \mathrm{~km}^{2}$ in Mauritania (Oudman et al., 2018). In other cases, animals may migrate to even broader regions. For example, seabirds, such as albatrosses and shearwaters, and marine mammals including many seals, may range widely over many tens of thousands of $\mathrm{km}$ as part of their migrations (Clay, Phillips, Manica, Jackson, \& Brooke, 2017; Dias, Granadeiro, Phillips, Hany, \& Paulo, 2010; Sztukowski et al., 2018). Given this range of migration patterns, assessing the cost and benefits of migration strategies remains a key question in movement ecology (Hays et al., 2016). 
55 Here we consider an enigmatic, but classic, group of migrators that may reveal some general reasons for why animals migrate and have fidelity to particular sites. Sea turtles are well known to migrate many thousands of $\mathrm{km}$ and to have fidelity to breeding sites (e.g. Jensen et al., 2013). ago capture-mark-recapture (CMR) studies in eastern Australia started to suggest that loggerhead turtles (Caretta caretta) and green turtles (Chelonia mydas), identified with numbered flipper tags, may have strong long-term fidelity to localised foraging sites (Limpus et al., 1992) with further evidence for this trait being provided more recently by satellite tracking (e.g. Broderick, Coyne, Fuller, Glen, \& Godley, 2007; Limpus \& Limpus, 2001). Yet at the same time, it has become apparent that within the same population, migration distances from breeding to foraging sites may vary from a few 10 s of km up to many 1000 s of km (e.g. Hays, Mortimer, Ierodiaconou, \& Esteban, 2014). Here, using satellite tracking data from multiple species across the Pacific, Atlantic, Indian Ocean, Mediterranean and Caribbean Sea, as well as a 50+ year CMR dataset, we explore the general applicability of foraging site fidelity in sea turtles across a broad range of migration distances and we develop a mechanistic understanding of the processes that may drive the observed patterns of fidelity.

\section{2 | MATERIALS AND METHODS}

As part of long-term satellite tracking studies in the western Indian Ocean and NE coast of Australia (Esteban, Mortimer, \& Hays, 2017; Hays et al., 2014; Limpus \& Limpus, 2001; 
Shimada, Limpus, et al., 2016), we satellite-tracked adult sea turtles from their breeding sites to their foraging sites (Supporting Information Table S1 which includes details of make and model of tags). In the central Indian Ocean, we equipped nesting green turtles with satellite tags on the island of Diego Garcia within the Chagos Archipelago. Results presented here came from deployment of Fastloc-GPS Argos tags, i.e. tags that relayed Fastloc-GPS data via the Argos network. On the NE coast of Australia, across 22 years, both Fastloc-GPS Argos tags, as well as Argos-only tags (i.e. tags from which Argos locations were obtained, but not Fastloc-GPS locations), were deployed on green, loggerhead, hawksbill (Eretmochelys imbricata), and flatback (Natator depressus) turtles on the nesting and/or foraging sites. From Fastloc-GPS Argos tags, highly accurate locations are obtained, with locations generally within a few tens of metres of the true position (Hazel, 2009). For tracks obtained with Argos-only tags, we used only high quality locations (location classes 3,2 and 1), which are generally within a kilometre of the true location (Hoenner, Whiting, Hindell, \& McMahon, 2012). We used the SDLfilter package in $\mathrm{R}$ (R Core Team, 2019) to improve the overall accuracy of tracking data by removing temporal and spatial duplicates, and suspect locations which are biologically unrealistic for each species based on the travel speed and turning angle (Shimada, Jones, Limpus, Groom, \& Hamann, 2016; Shimada, Jones, Limpus, \& Hamann, 2012).

For each track, we identified foraging sites based on the changes in speed of travel, as is done routinely (Schofield et al., 2010). First, we visually identified the track segment during which a turtle was clearly migrating between the foraging and breeding site, and calculated a 2-day average of the migration speed at each location. Each turtle was considered to have arrived at its 
foraging site once the speed was below the minimum migration speed of each track. In cases when turtles were originally tracked from the foraging site, they returned to the same foraging sites, or in cases where tags were attached to nesting turtles, locations continued to be obtained on the foraging site for $>1$ months until tags failed, confirming the end point of migration has been identified. Similarly, a turtle was considered to have left the foraging site, on its migration to breed, once the 2-day averaged speed exceeded its minimum migration speed.

To quantify the extent of foraging site fidelity, we calculated the midpoint of the foraging site location for dates separated by migration to breed. The mid-point of the foraging site location was determined as either: (1) the mean location obtained on the foraging site, using either Fastloc-GPS or Argos locations; (2) if tracking data were lacking, the mean capture location of an individual. So, for some individuals we compared tracking data across dates separated by a migration to breed. For example, from a single satellite tag deployment an individual was tracked from its foraging site to its breeding site and back; or an individual was equipped with a satellite tag while breeding in different years. In other cases, we tracked an individual from its breeding site and compared the post-breeding foraging site with a previous capture location.

To visually identify the home-range for turtles equipped with Fastloc-GPS tags, foraging site home range was plotted as the $95 \%$ volume contour of a utilisation distribution (UD). We used a movement-based kernel density estimator based on a biased random bridge (Benhamou, 2011) to estimate a UD from each Fastloc GPS track. The spatial resolution was $50 \mathrm{~m}$ and the other parameters required for UD estimation were adopted from Benhamou (2011) and Shimada et al. 
121 (2016). The R package adehabitatHR (Calenge, 2006) was used to estimate a UD and delineate

122 the $95 \%$ volume contour. We only completed this analysis with Fastloc-GPS locations, because

123 their high accuracy allows reliable estimates of overall space use to be determined (Thomson et

124 al., 2017).

125

126 To assess the temporal scale of fidelity to foraging sites we examined 2001 re-sightings of turtles

127 marked with flipper tags while breeding and then re-sighted at foraging sites. The data source is

128 the Queensland Turtle Conservation Project (QTCP) database, which contains almost half a

129 million capture records from 172,661 tagged turtles, gathered across $50+$ years along the NE

130 coast of Australia and neighboring countries (Queensland Environmental Protection Agency,

131 2018). Foraging site locations of flipper tagged turtles were used to document the known

132 foraging sites for each species and, in this way, we examined if turtles equipped with satellite

133 tags travelled through foraging areas used by conspecifics.

134

135 In addition to the unpublished satellite tracks, we also examined the QTCP database and the

136 literature for similar datasets where adult sea turtles were recorded at their foraging sites and

137 later, either satellite-tracked from their breeding sites or recorded successively at their breeding

138 and foraging sites. We examined literature cited by the highly-cited seminal study (Broderick et

139 al., 2007), and by the subsequent 282 publications which cited the Broderick study (Google

140 Scholar - 24 July 2019). Once relevant literature were identified, we further examined the

141 references cited within. In doing so we assessed the generality, across species, of whether 
142 individuals show fidelity to previously used foraging sites. Tracks in the literature with suspect

143 premature transmitter failures were not included in this review (e.g. Luschi et al., 2013).

\section{3 | RESULTS}

147

148 We satellite-tracked a total of 27 individuals whose previously used foraging locations were 149 known (Supporting Information Table S1), one turtle in the Indian Ocean and 26 in NE Australia 150 (Supporting Information Figure S1). Individuals spanned multiple species: $n=13$ green turtles, $n$ $151=11$ loggerhead turtles, $\mathrm{n}=1$ hawksbill turtle and $\mathrm{n}=2$ flatback turtles. In all cases we obtained 152 evidence that individuals returned to foraging sites they had used previously. For example, where 153 individuals were satellite-tracked before and after a breeding season, locations obtained at the 154 foraging sites before and after breeding were intermingled showing individuals were using 155 broadly the same area. Before and after migrations to breed, the mean distance between the mid156 point of the locations on the foraging site was only $7 \mathrm{~km}(\mathrm{n}=27$, range $=<1-25 \mathrm{~km})$. This tight 157 fidelity was maintained across long migrations, with the mean distance travelled between the 158 breeding site and the foraging sites being $508 \mathrm{~km}$ (range $=14-4810 \mathrm{~km})$. So tight fidelity to 159 foraging sites was always observed.

Individuals from all four species often travelled through areas used by their conspecifics, and 162 returned to their home foraging site. We showcase some selected examples in Figure 1 to 
163 highlight how foraging site fidelity was maintained after very long distance breeding migrations 164 and also over many years.

165

166
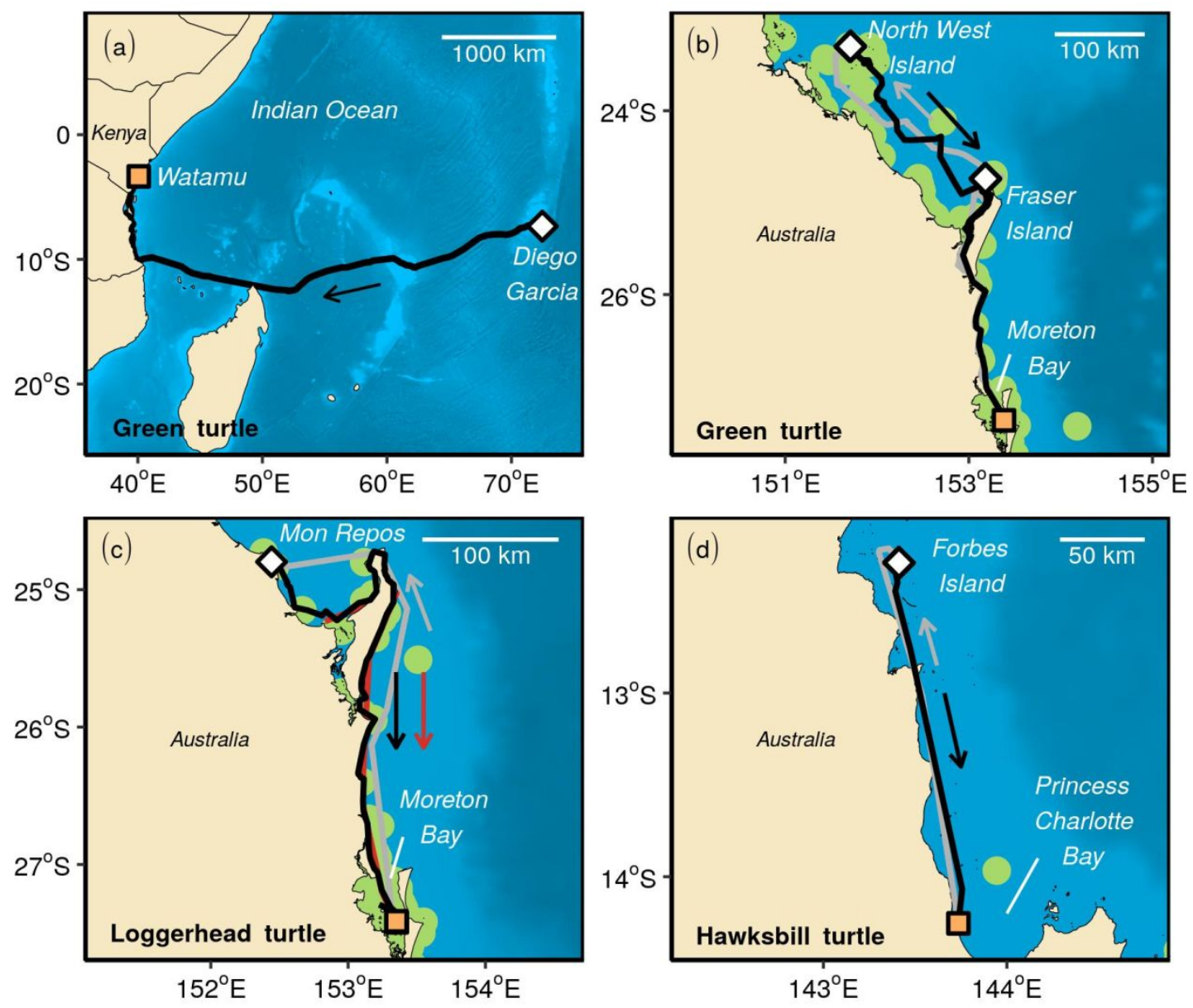

167 FIGURE 1 Examples of satellite tracks of turtles that, after breeding, returned to previously used

168 foraging sites (orange square $=$ flipper tagging location on foraging site; white diamond =

169 nesting site; black line $=1$ st migration route, red line $=2$ nd migration route, grey line $=$

170 migration route to breeding site; green circle $=$ known foraging sites inferred from flipper tag

171 recapture of each species). (a) Post-nesting migration of a green turtle (KE0633) equipped with a

172 Fastloc-GPS satellite tag on the island of Diego Garcia in 2015 and tracked to its foraging site

173 off the coast of Watamu, Kenya, a site where it was captured 12 years prior and flipper tagged. 
174 (b) A green turtle (QA11747) captured and released with a satellite tag at the foraging site in 175 Moreton Bay, 57 days before the breeding migration in 2010. It was then tracked during 176 breeding migration to its nesting site on Fraser Island and North West Island and back to its 177 foraging site in Moreton Bay. (c) A loggerhead turtle (T14914) satellite-tracked twice in

different years. In 1996/1997 it was tracked from the foraging site in Moreton Bay to the Mon

Repos nesting beach, and back to its foraging site in Moreton Bay. It was again equipped with a satellite tag on the Mon Repos nesting beach in 2010 and tracked back to its foraging site in Moreton Bay until transmissions ceased in 2013. (d) A hawksbill turtle (QA40538) captured on the foraging site in Princess Charlotte Bay before the breeding migration in 2014. It was satellitetracked to its nesting site on Forbes Island, and back to its foraging site.

Tracking with Argos-linked Fastloc GPS tags allowed detailed foraging site home ranges used across different years to be assessed and further highlighted overlap between home ranges used across different years (Figure 2; Supporting Information Figure S2). For example, a loggerhead turtle (T93038) was tracked during post-nesting migration in 2010 and 2012, and following each migration had foraging home range centred on a coastal bay (Moreton Bay) $310 \mathrm{~km}$ distant from the nesting beach (Mon Repos), with the home range spanning around $20 \mathrm{~km}$ (Figure 2a;

Supporting Information Figure S1v). Additionally, this turtle had been captured in 1997 within its 2012 home range (Figure 2a). During these 15.5 years, it migrated to breed at least 7 times, as evidenced from recapture records at the nesting beaches (Supporting Information Table S1). 
196

197

198

199

200

201

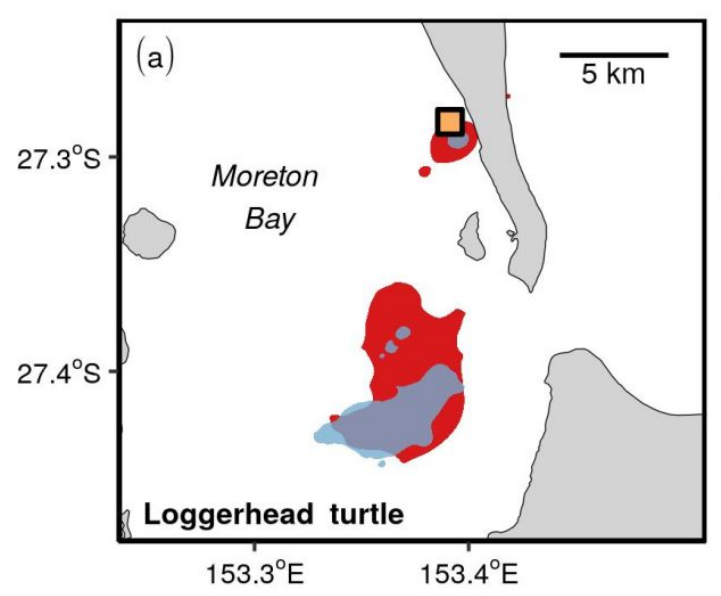

Another example is a flatback turtle (T20452) whose post-nesting migration was tracked twice with a four-year gap in-between. In each case, the foraging home range was located to the northwest of Shoalwater Bay, $270 \mathrm{~km}$ distant from the nesting beach (Curtis Island), with the home range spanning $76 \mathrm{~km}$ across (Figure 2b; Supporting Information Figure S1z).

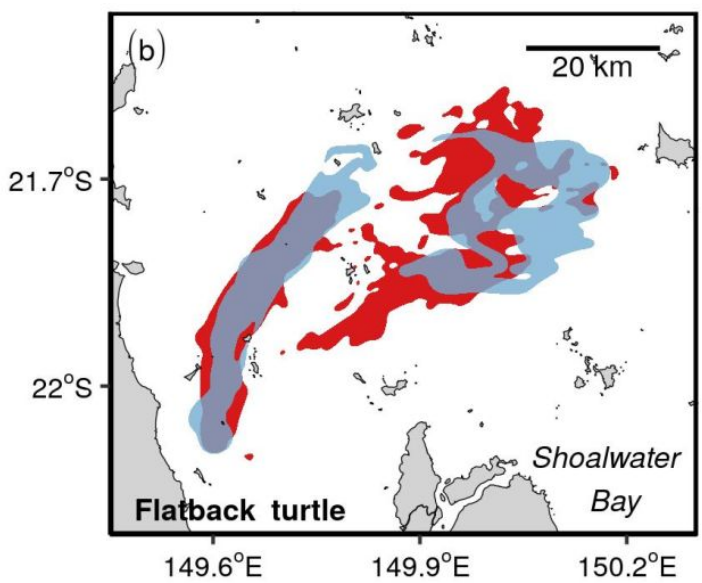

202

203

204

205

206

207

208

209

210

FIGURE 2 Detailed patterns of space use by sea turtles who were satellite-tracked from their nesting sites to their foraging sites in different years. In these examples, home ranges $(95 \%$ utilisation distributions - polygons) were determined from Fastloc GPS locations obtained during two separate tracking occasions; 1st time = light blue, 2nd time = red. (a) A loggerhead turtle (T93038) originally captured and tagged with a numbered flipper tag in 1997 (orange square) and then tracked on its post-breeding foraging site for 104 days (1208 Fastloc-GPS locations obtained) in 2010, and then again for 280 days (653 Fastloc-GPS locations obtained) in 2012 after another post-breeding migration. (b) A flatback turtle (T20452) tracked on its foraging site for 544 days (1314 Fastloc-GPS locations obtained) in 2010 and then again for 39 days (212 
211 Fastloc-GPS locations obtained) in 2014 following two separate post-nesting migrations. These

212 examples show how the foraging areas used across multiple years were very similar.

From the QTCP database, we obtained CMR records of 175 flipper-tagged turtles, who were recorded at foraging sites up to 51 times, spanning up to 29 years, with breeding records of up to 6 separate breeding seasons between foraging area captures (Supporting Information Table S2). maturity, and continued to do so after reaching maturity and subsequent breeding migrations

232 (Supporting Information Table S2). One unique example is a loggerhead turtle (T93076) with its 
233 capture history spanning 40 years. It was originally tagged as a hatchling leaving its natal beach,

234 Mon Repos, in February 1975, recaptured as an immature female foraging and growing up on the

235

236

237

238

239

240

241

242

243

244

245

246

247

248

249

250

251

252

253

254 eastern banks of Moreton Bay in 1997, 1998, 2000 and 2001. At 29 years of age, it returned to its natal beach during the December 2004 - January 2005 summer to breed for the first time (confirmed by gonad examination), and laid 2 clutches of eggs. In April 2005 it was recaptured again foraging on the eastern Banks of Moreton Bay. It returned at 39 years of age to its natal beach, Mon Repos, for its second breeding season in the 2014-2015 summer during which it laid 3 clutches of eggs. In September 2015 it was recaptured again foraging on the eastern banks of Moreton Bay, exactly the same site as it was originally captured at 18 years ago as an immature turtle. This turtle is displaying fidelity to both a chosen nesting beach, which was also its natal beach and to the foraging site it chose as an immature turtle and in which it grew to maturity.

From the literature we compiled 76 previously published satellite tracks of 43 individuals (some were equipped with satellite tags more than once), where the post-breeding migrations were documented for individuals whose foraging areas had been previously known. These examples comprised 11 female loggerhead, 1 female hawksbill and 7 female kemp's ridley turtles in the Caribbean (Hart, Sartain, \& Fujisaki, 2015; Hawkes et al., 2012; Shaver \& Rubio, 2008; Tucker, MacDonald, \& Seminoff, 2014); 3 female green and 11 loggerhead turtles ( 5 female, 6 male) in the Mediterranean (Broderick et al., 2007; Casale, Freggi, Cinà, \& Rocco, 2013; Mingozzi, Mencacci, Cerritelli, Giunchi, \& Luschi, 2016; Schofield et al., 2010); 5 female loggerhead turtles in Brazil (Marcovaldi et al., 2010); 5 female loggerhead turtles in NE Australia (Limpus \& Limpus, 2001). In addition we considered 3 green turtles ( 1 female, 2 male) equipped with 
255 diving loggers while at their foraging sites in Hawaii, who were tracked to the breeding site, as 256 evidenced from the logged dive data, and subsequently relocated at foraging sites and the dive 257 loggers removed (Rice \& Balazs, 2008). So new and existing data all combined, a total of 243 258 individuals of five species, whose previous foraging areas were known, were satellite-tracked 259 260 261 previously.

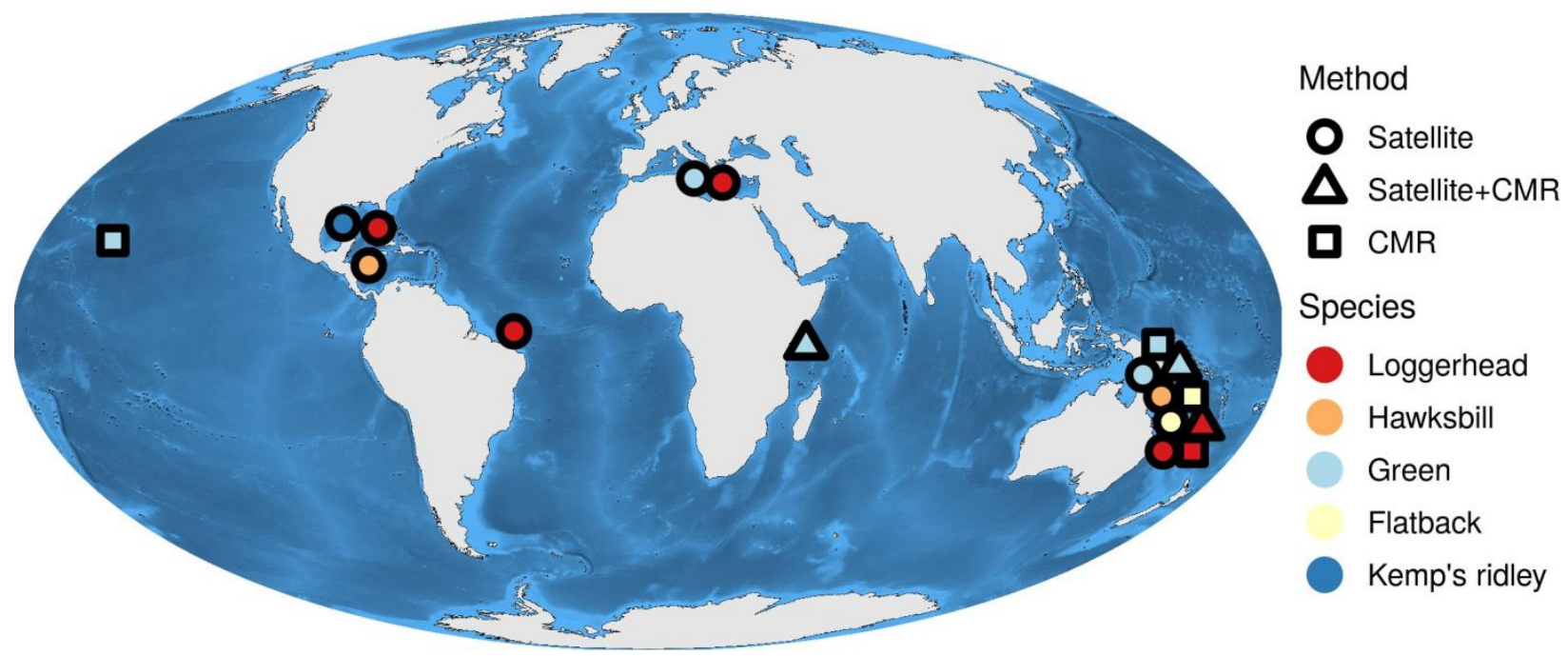

FIGURE 3 Locations around the world where adult breeding sea turtles, whose previous foraging areas were known, have been equipped with electronic or flipper tags to record their

267 foraging sites after post-breeding migrations. In all cases individuals returned to foraging areas they had used previously. Foraging sites were identified by entirely satellite telemetry, a 
269

270

271

272

273

274

275

276

277

278

279

280

281

282

283

284

285

286

287

288

289

290

3

combination of satellite telemetry and capture-mark-recapture (CMR), or solely CMR. Species are colour-coded. See text for details.

\section{4 | DISCUSSION}

Key conclusions from our study are that fidelity to specific localised foraging sites following migrations to breed, seems to be a common trait across several species of sea turtle; this fidelity can occur after very long migrations, with some individuals travelling up to $10,000 \mathrm{~km}$ to-andfrom their breeding sites; this fidelity occurs over long-periods of up to at least 29 years; and individuals often travel through areas used by conspecifics en route to their foraging site.

Foraging site fidelity after long journeys, and foregoing potential foraging sites en route, has also been observed in other taxa such as birds and seals (Aharon-Rotman, Buchanan, Clark, Klaassen, \& Buttemer, 2016; Bonadonna, Lea, Dehorter, \& Guinet, 2001), suggesting that the trait might be driven by common selective pressures acting across taxa.

4 A mechanistic understanding for why taxa may show tight fidelity to localised foraging sites following migration versus having a more nomadic existence, may be centred on the patterns and predictability of prey resources and the risks involved in relocating to new sites. At one extreme, the tight foraging site fidelity that we reported contrasts with some other marine taxa that may show regional fidelity to certain broad foraging sites, but still travel extensively while foraging in a nomadic way of life (Teitelbaum \& Mueller, 2019). For example, some sea birds, marine mammals and pelagic turtles (e.g. the leatherback, Dermochelys coriacea) can travel extensively 
291

292

293

outside the breeding season, foraging across broad expanses of ocean basins (Hays, Hobson, Metcalfe, Righton, \& Sims, 2006; James, Ottensmeyer, \& Myers, 2005; McIntyre, Bester, Bornemann, Tosh, \& de Bruyn, 2017). In these cases, the lack of tight fidelity is presumably related to the nature of their prey as well as environmental conditions, with animals wandering over large areas in a semi-predictable manner to search for patchily distributed prey while also being constrained by an environmental niche such as their temperature tolerances (McIntyre et al., 2017; Sousa, Queiroz, Mucientes, Humphries, \& Sims, 2016; Sztukowski et al., 2018; Teitelbaum \& Mueller, 2019). Compared to these oceanic foragers, for animals not feeding in pelagic open-ocean sites, such as sea turtles foraging on the seabed in coastal areas or wading birds feeding in shallow wetlands, forage quality may be more predictable. Certainly the sea turtle species with demonstrated foraging site fidelity are largely benthic foragers. For example, green turtles are largely herbivorous feeding on seagrasses and macroalgae, hawksbill turtles tend to feed on sponges or algae in reef habitats and loggerhead turtles consume a range of benthic invertebrates such as bivalve molluscs (Bjorndal, 1997). For all these benthic prey taxa, there may often be relatively stable levels of abundance in particular areas, such as the occurrence of sponges on particular coral reefs or seagrasses in particular seagrass meadows (Diaz \& Rützler, 2001; Duarte \& Chiscano, 1999), contrasting to the more ephemeral, localised abundance of pelagic prey resources such as plankton and fish. So, for benthic foragers, foraging areas may have long-term suitability. However, the particular foraging site of some sea turtles and other taxa, such as wading birds, cannot alone explain why individuals transit through areas with suitable forage encountered en route which will incur some costs. 
313 Migrating an extra distance will first impose a metabolic cost of travelling further, for example

314 the cost of swimming for a sea turtle or flying for a bird. Second is the opportunity cost of

315 missed time spent foraging since individuals will be away from their foraging sites for longer.

316 Both of these costs may be appreciable. For example, for sea turtles the oxygen consumption has

317 been measured directly for individuals swimming in respirometry chambers, with metabolic rates

318 while swimming being up to $3-4 x$ the resting metabolic rate (Prange, 1976). Similarly, using data

319 from acceleration loggers, Enstipp et al. (2016) estimated that the metabolic rate of migrating

320 green turtles was $3 \mathrm{x}$ the resting metabolic rate, equating to $2327 \mathrm{~kJ}$ day ${ }^{-1}$. The estimated energy

321 content of a single green turtle egg has been estimated at $279.5 \mathrm{~kJ}$ (Hays \& Scott, 2013) and the

322 mean clutch size measured at 113 eggs (Miller, 1997). So the estimated energy expenditure

323 during 13.6 days of migration, equates to the energy content of about one clutch. This model

324 does not account for opportunistic energy intake during migration that may happen in the same

325 way that turtles feed on gelatinous prey in their home foraging areas (Arthur, O’Neil, Limpus,

326 Abernathy, \& Marshall, 2007). Nonetheless, this simple calculation suggests that migrating long

327 distances involves a considerable amount of energy, which may reduce reproductive output.

328 Added to this metabolic cost of swimming will be the reduction of time at foraging sites. For

example, if a green turtle returns to breed every 3 years, spends 8 days mating and 12 days

330 preparing the first clutch of eggs at the breeding area (i.e. 20 days), and lays 6 clutches at 12 day

331 intervals (i.e. 60 days) (Esteban et al., 2017; Miller, 1997), then in the absence of any migration,

332 individuals would be at the foraging site for $(365 \times 3)-(20+60)=1015$ days. Migrating, for

333 example, $4000 \mathrm{~km}$ from the foraging area to the breeding area (i.e. a round trip of $8000 \mathrm{~km}$ ) at a 
334 speed of $50 \mathrm{~km}$ per day, would necessitate 80 days of travel each way, reducing the time spent on 335 at foraging sites by $15.8 \%$ to 855 days.

337 Given these extra costs (both energy expended and reduced foraging time) of migrating long

distances, there are presumably important counterbalancing selective pressures underpinning the

340 sites used by conspecifics, thus with potential suitable forage. A key benefit of foraging site

fidelity is that individuals will have a previous knowledge of that area and know that they can

342 survive in that area for long periods. This benefit presumably outweighs an imperfect knowledge of sites encountered en route that may have suitable food but whose long-term quality is unknown. Furthermore for these sites encountered en route, migrators will likely have an incomplete knowledge of seasonal changes in conditions, the extent of competition with conspecifics and the threat from predators, all factors that may impact an area's suitability

347 (Heithaus et al., 2007). Hence there is a risk for an individual to relocate to a new site encountered during migration. In these situations, selective pressure across many sea turtle species seems to have favored an individual returning to the area which had served it well allowing it to survive and attain sufficient body condition to enable successful breeding. In support of these ideas, when comparing migrating wading birds that end their migration early compared to those that forgo foraging areas en route and travel further, individuals migrating further have been shown to have lower levels of stress biomarkers and higher feeding rates (Aharon-Rotman et al., 2016). 
While there are clearly substantial benefits for sea turtles and other taxa to travel long distances to previously used localised foraging sites, occasionally the foraging conditions will degrade, for example due to environmental perturbations such as heatwaves (Arias-Ortiz et al., 2018). In these situations, relocation to a new foraging site, even if the knowledge of that new site is imperfect, may be a better decision rather than remaining in place and risking reduced breeding rates or possibly dying. One example that fits to this theory is the loggerhead turtle that appears to have moved its foraging site temporarily from Hervey Bay to Moreton Bay, sites approximately $270 \mathrm{~km}$, when two floods and a tropical cyclone caused a loss of $>1000 \mathrm{~km}^{2}$ of benthic habitat in Hervey Bay followed by an elevated number of stranded sea turtles (green, loggerhead, flatback) and dugongs (Preen \& Marsh, 1995; Preen, Lee Long, \& Coles, 1995; Supporting Information Figure S5). However, notwithstanding this particular case, the decision to "move or face death" was very rare in both our study and others. Rather than relocating, a turtle may usually simply endure temporary degradation of its foraging site aided by its low ectothermic metabolic rate which ensure long fasting endurance and slow use of stored fat reserves (Hays, Broderick, Glen, \& Godley, 2002). The same strategy of fasting is less likely for endotherms as their higher metabolic rate means they have much shorter fasting endurance than an equivalent sized ectotherm and indeed, breakdowns in fidelity to foraging sites has been noted in marine mammals and birds (Dias et al., 2010; Knox, Baylis, \& Arnould, 2018). While foraging site fidelity in sea turtles will limit the flexibility of individuals to colonise new areas, the dispersal of the young from a single genetic stock to multiple widely scattered foraging areas, for example driven by variable ocean currents (Hays, Fossette, Katselidis, Mariani, \& Schofield, 2010) has the potential to ensure that populations can respond to spatially and temporally 
378 changing availability of food resources and survival probabilities, for example driven by climate 379 change.

380

381 In conclusion, we show here that tight fidelity to foraging sites occurs after long (sometimes $382>1000 \mathrm{~km}$ ) breeding migrations for a range of sea turtle species that feed in coastal areas. This is 383 presumably linked to imprinting on an area where the individual has a substantial knowledge and 384 survived for a long period, versus moving to risky alternate sites where an individual's 385 knowledge is much less complete.

\section{5 | ETHICS}

This research was conducted following all applicable guidelines for the care and use of animals approved by the Ethics Committee of the Queensland Department of Environment and Science (DES), James Cook University, Swansea University and Deakin University.

\section{ACKNOWLEDGMENTS}

T.S., C.L., M.H., I.B. \& R.G. thank staff of Queensland Parks and Wildlife Service, staff of Torres Strait Regional Authority, Torres Strait communities, and numerous volunteers for their support of research in Australia. N.E. thanks Richard Zanre, Nicky Parazzi, Casper van de Geer and Kahindi from Local Ocean Trust in Kenya for information about turtle KE0633. The work of G.C.H. and N.E. in the Chagos Archipelago was supported by the Bertarelli Foundation as part 399 of the Bertarelli Programme in Marine Science (BPMS-2017-4). Research in Australia was 
400 funded by DES, Gladstone Port Corporation, Sea World, Healthy Waterways, and Bundaberg 401 Brewed Drinks.

402

403 CONFLICT OF INTEREST

404 The authors declare no conflicts of interest.

405

406 AUTHOR CONTRIBUTIONS

407 G.C.H. conceived the study with T.S. T.S. and G.C.H. analysed the data and wrote the paper 408 with input from all authors building on life history concepts previously developed by C.L. from with T.S. and R.G. G.C.H. and NE conducted the Indian Ocean fieldwork.

DATA ACCESSIBILITY

414 Tracking data are archived on www.movebank.org. Request for data should be addressed to 415 t.shimada@aims.gov.au.

\section{REFERENCES}

Aharon-Rotman, Y., Buchanan, K. L., Clark, N. J., Klaassen, M., \& Buttemer, W. A. (2016). Why fly the extra mile? Using stress biomarkers to assess wintering habitat quality in migratory shorebirds. Oecologia, 182(2), 385-395. doi: 10.1007/s00442-016-3679-1

Alerstam, T., Hedenström, A., \& Åkesson, S. (2003). Long-distance migration: evolution and 
determinants. Oikos, 103(2), 247-260. doi: 10.1034/j.1600-0706.2003.12559.x

Arias-Ortiz, A., Serrano, O., Masqué, P., Lavery, P. S., Mueller, U., Kendrick, G. A., ... Duarte, C. M. (2018). A marine heatwave drives massive losses from the world's largest seagrass carbon stocks. Nature Climate Change, 8(4), 338. doi: 10.1038/s41558-018-0096-y

Arthur, K. E., O’Neil, J. M., Limpus, C. J., Abernathy, K., \& Marshall, G. (2007). Using animal-borne imaging to assess green turtle (Chelonia mydas) foraging ecology in Moreton Bay, Australia. Marine Technology Society Journal, 41(4), 9-13. doi: 10.4031/002533207787441953

Benhamou, S. (2011). Dynamic approach to space and habitat use based on biased random bridges. PLoS ONE, 6(1), e14592-e14592. doi: 10.1371/journal.pone.0014592

Bett, N. N., \& Hinch, S. G. (2016). Olfactory navigation during spawning migrations: a review and introduction of the Hierarchical Navigation Hypothesis. Biological Reviews, 91(3), 728-759. doi: $10.1111 /$ brv. 12191

Bjorndal, K. A. (1997). Foraging ecology and nutrition of sea turtles. In P. L. Lutz \& J. A. Musick (Eds.), The biology of sea turtles: Vol. I (pp. 199-231). doi: 10.1201/9780203737088

Bonadonna, F., Lea, M.-A., Dehorter, O., \& Guinet, C. (2001). Foraging ground fidelity and route-choice tactics of a marine predator: the Antarctic fur seal Arctocephalus gazella. Marine Ecology Progress Series, 223, 287-297. doi: 10.3354/meps223287

Broderick, A. C., Coyne, M. S., Fuller, W. J., Glen, F., \& Godley, B. J. (2007). Fidelity and overwintering of sea turtles. Proceedings of the Royal Society B: Biological Sciences, 274(1617), 1533-1539. doi: 10.1098/rspb.2007.0211

Calenge, C. (2006). The package "adehabitat" for the R software: A tool for the analysis of space and habitat use by animals. Ecological Modelling, 197(3-4), 516-519. doi:

10.1016/j.ecolmodel.2006.03.017

Casale, P., Freggi, D., Cinà, A., \& Rocco, M. (2013). Spatio-temporal distribution and migration of adult male loggerhead sea turtles (Caretta caretta) in the Mediterranean Sea: further evidence of the 
importance of neritic habitats off North Africa. Marine Biology, 160(3), 703-718. doi: $10.1007 / \mathrm{s} 00227-012-2125-0$

Clay, T. A., Phillips, R. A., Manica, A., Jackson, H. A., \& Brooke, M. de L. (2017). Escaping the oligotrophic gyre? The year-round movements, foraging behaviour and habitat preferences of Murphy's petrels. Marine Ecology Progress Series, 579, 139-155. doi: 10.3354/meps 12244

Dias, M. P., Granadeiro, J. P., Phillips, R. A., Hany, A., \& Paulo, C. (2010). Breaking the routine: individual Cory's shearwaters shift winter destinations between hemispheres and across ocean basins. Proceedings of the Royal Society B: Biological Sciences, 278(1713), 1786-1793. doi: $10.1098 /$ rspb.2010.2114

Diaz, M. C., \& Rützler, K. (2001). Sponges: An essential component of Caribbean coral reefs. Bulletin of Marine Science, 69(2), 535-549.

Duarte, C. M., \& Chiscano, C. L. (1999). Seagrass biomass and production: a reassessment. Aquatic Botany, 65(1), 159-174. doi: 10.1016/S0304-3770(99)00038-8

Enstipp, M. R., Ballorain, K., Ciccione, S., Narazaki, T., Sato, K., \& Georges, J.-Y. (2016). Energy expenditure of adult green turtles (Chelonia mydas) at their foraging grounds and during simulated oceanic migration. Functional Ecology, 30(11), 1810-1825. doi: 10.1111/13652435.12667

Esteban, N., Mortimer, J. A., \& Hays, G. C. (2017). How numbers of nesting sea turtles can be overestimated by nearly a factor of two. Proceedings of the Royal Society B: Biological Sciences, 284(1849). doi: 10.1098/rspb.2016.2581

Hart, K. M., Sartain, A. R., \& Fujisaki, I. (2015). Bahamas connection: residence areas selected by breeding female loggerheads tagged in Dry Tortugas National Park, USA. Animal Biotelemetry, 3(1). doi: 10.1186/s40317-014-0019-2

Hawkes, L. A., Tomás, J., Revuelta, O., León, Y. M., Blumenthal, J. M., Broderick, A. C., ... Godley, B. J. (2012). Migratory patterns in hawksbill turtles described by satellite tracking. Marine Ecology 
Progress Series, 461, 223-232. doi: 10.3354/meps09778

Hays, G. C., Broderick, A. C., Glen, F., \& Godley, B. J. (2002). Change in body mass associated with long-term fasting in a marine reptile: the case of green turtles (Chelonia mydas) at Ascension Island. Canadian Journal of Zoology, 80(7), 1299-1302. doi: 10.1139/z02-110

Hays, G. C., Ferreira, L. C., Sequeira, A. M. M., Meekan, M. G., Duarte, C. M., Bailey, H., ... Thums, M. (2016). Key questions in marine megafauna movement ecology. Trends in Ecology \& Evolution, 31(6), 463-475. doi: 10.1016/j.tree.2016.02.015

Hays, G. C., Fossette, S., Katselidis, K. A., Mariani, P., \& Schofield, G. (2010). Ontogenetic development of migration: Lagrangian drift trajectories suggest a new paradigm for sea turtles. Journal of the Royal Society Interface, 7(50), 1319-1327. doi: 10.1098/rsif.2010.0009

Hays, G. C., Hobson, V. J., Metcalfe, J. D., Righton, D., \& Sims, D. W. (2006). Flexible foraging movements of leatherback turtles across the north Atlantic Ocean. Ecology, 87(10), 2647-2656. doi: 10.1890/0012-9658(2006)87[2647:FFMOLT]2.0.CO;2

Hays, G. C., Mortimer, J. A., Ierodiaconou, D., \& Esteban, N. (2014). Use of long-distance migration patterns of an endangered species to inform conservation planning for the world's largest marine protected area. Conservation Biology, 28(6), 1636-1644. doi: 10.1111/cobi.12325

Hays, G. C., \& Scott, R. (2013). Global patterns for upper ceilings on migration distance in sea turtles and comparisons with fish, birds and mammals. Functional Ecology, 27(3), 748-756. doi: $10.1111 / 1365-2435.12073$

Hazel, J. (2009). Evaluation of fast-acquisition GPS in stationary tests and fine-scale tracking of green turtles. Journal of Experimental Marine Biology and Ecology, 374(1), 58-68. doi: 10.1016/j.jembe.2009.04.009

Heithaus, M. R., Frid, A., Wirsing, A. J., Dill, L. M., Fourqurean, J. W., Burkholder, D., ... BejderO, L. (2007). State-dependent risk-taking by green sea turtles mediates top-down effects of tiger shark intimidation in a marine ecosystem. Journal of Animal Ecology, 76(5), 837-844. doi: 
$10.1111 / \mathrm{j} .1365-2656.2007 .01260 . \mathrm{x}$

Hoenner, X., Whiting, S. D., Hindell, M. A., \& McMahon, C. R. (2012). Enhancing the use of argos satellite data for home range and long distance migration studies of marine animals. PloS One, 7(7), e40713-e40713. doi: 10.1371/journal.pone.0040713

James, M. C., Ottensmeyer, C. A., \& Myers, R. A. (2005). Identification of high-use habitat and threats to leatherback sea turtles in northern waters: new directions for conservation. Ecology Letters, $8(2)$, 195-201. doi: 10.1111/j.1461-0248.2004.00710.x

Jensen, M. P., FitzSimmons, N. N., \& Dutton, P. H. (2013). Molecular genetics of sea turtles. In J. Wyneken, K. J. Lohmann, \& J. A. Musick (Eds.), The biology of sea turtles: Vol. III (1 st ed., pp. 135-161). Boca Raton, FL: CRC Press.

Knox, T. C., Baylis, A. M. M., \& Arnould, J. P. Y. (2018). Foraging site fidelity in male Australian fur seals. Marine Biology, 165(7), 108. doi: 10.1007/s00227-018-3368-1

Limpus, C. J., \& Limpus, D. J. (2001). The loggerhead turtle, Caretta caretta, in Queensland: breeding migrations and fidelity to a warm temperate feeding area. Chelonian Conservation and Biology, $4(1), 142-153$.

Limpus, C. J., Miller, J. D., Parmenter, C. J., Reimer, D., Mclachlan, N., \& Webb, R. (1992). Migration of green (Chelonia mydas) and loggerhead (Caretta caretta) turtles to and from eastern Australian rookeries. Wildlife Research, 19(3), 347-358. doi: 10.1071/WR9920347

Luschi, P., Mencacci, R., Vallini, C., Ligas, A., Lambardi, P., \& Benvenuti, S. (2013). Long-term tracking of adult loggerhead turtles (Caretta caretta) in the Mediterranean Sea. Journal of Herpetology, 47(2), 227-231. doi: 10.1670/11-173

Marcovaldi, M. Â., Lopez, G. G., Soares, L. S., Lima, E., Thomé, J. C. A., \& Almeida, A. P. (2010). Satellite-tracking of female loggerhead turtles highlights fidelity behavior in northeastern Brazil. Endangered Species Research, 12(3), 263-272. doi: 10.3354/esr00308

McIntyre, T., Bester, M. N., Bornemann, H., Tosh, C. A., \& de Bruyn, P. J. N. (2017). Slow to change? 
Individual fidelity to three-dimensional foraging habitats in southern elephant seals, Mirounga leonina. Animal Behaviour, 127, 91-99. doi: 10.1016/j.anbehav.2017.03.006

Miller, J. D. (1997). Reproduction in sea turtles. In P. L. Lutz \& J. A. Musick (Eds.), The biology of sea turtles: Vol. I (pp. 51-81). Florida: CRC Press.

Mingozzi, T., Mencacci, R., Cerritelli, G., Giunchi, D., \& Luschi, P. (2016). Living between widely separated areas: Long-term monitoring of Mediterranean loggerhead turtles sheds light on cryptic aspects of females spatial ecology. Journal of Experimental Marine Biology and Ecology, 485, 817. doi: $10.1016 /$ j.jembe.2016.08.007

Oudman, T., Piersma, T., Ahmedou Salem, M. V., Feis, M. E., Dekinga, A., Holthuijsen, S., ... Bijleveld, A. I. (2018). Resource landscapes explain contrasting patterns of aggregation and site fidelity by red knots at two wintering sites. Movement Ecology, 6(1), 24. doi: 10.1186/s40462-018-0142-4

Prange, H. D. (1976). Energetics of swimming of a sea turtle. Journal of Experimental Biology, 64(1), 112.

Preen, A., \& Marsh, H. (1995). Response of dugongs to large-scale loss of seagrass from Hervey Bay, Queensland Australia. Wildlife Research, 22(4), 507-519. doi: 10.1071/WR9950507

Preen, A. R., Lee Long, W. J., \& Coles, R. G. (1995). Flood and cyclone related loss, and partial recovery, of more than $1000 \mathrm{~km}^{2}$ of seagrass in Hervey Bay, Queensland, Australia. Aquatic Botany, 52(1), 3-17. doi: 10.1016/0304-3770(95)00491-H

Queensland Environmental Protection Agency. (2018). Queensland Turtle Conservation Project database.

R Core Team. (2019). R: a language and environment for statistical computing (Version v. 3.5.3). Retrieved from https://www.r-project.org

Rice, M. R., \& Balazs, G. H. (2008). Diving behavior of the Hawaiian green turtle (Chelonia mydas) during oceanic migrations. Journal of Experimental Marine Biology and Ecology, 356(1-2), 121127. doi: $10.1016 /$ j.jembe.2007.12.010 
Schofield, G., Hobson, V. J., Fossette, S., Lilley, M. K. S., Katselidis, K. A., \& Hays, G. C. (2010). Fidelity to foraging sites, consistency of migration routes and habitat modulation of home range by sea turtles. Diversity and Distributions, 16(5), 840-853. doi: 10.1111/j.14724642.2010.00694.x

Shaver, D. J., \& Rubio, C. (2008). Post-nesting movement of wild and head-started Kemp's ridley sea turtles Lepidochelys kempii in the Gulf of Mexico. Endangered Species Research, 4(1-2), 43-55. doi: $10.3354 /$ esr00061

Shimada, T., Jones, R., Limpus, C., Groom, R., \& Hamann, M. (2016). Long-term and seasonal patterns of sea turtle home ranges in warm coastal foraging habitats: Implications for conservation. Marine Ecology Progress Series, 562, 163-179. doi: 10.3354/meps11972

Shimada, T., Jones, R., Limpus, C., \& Hamann, M. (2012). Improving data retention and home range estimates by data-driven screening. Marine Ecology Progress Series, 457, 171-180. doi: $10.3354 /$ meps09747

Shimada, T., Limpus, C., Jones, R., Hazel, J., Groom, R., \& Hamann, M. (2016). Sea turtles return home after intentional displacement from coastal foraging areas. Marine Biology, 163(1), 8. doi: $10.1007 / \mathrm{s} 00227-015-2771-0$

Sousa, L. L., Queiroz, N., Mucientes, G., Humphries, N. E., \& Sims, D. W. (2016). Environmental influence on the seasonal movements of satellite-tracked ocean sunfish Mola mola in the northeast Atlantic. Animal Biotelemetry, 4(7). doi: 10.1186/s40317-016-0099-2

Sztukowski, L. A., Cotton, P. A., Weimerskirch, H., Thompson, D. R., Torres, L. G., Sagar, P. M., ... Votier, S. C. (2018). Sex differences in individual foraging site fidelity of Campbell albatross. Marine Ecology Progress Series, 601, 227-238. doi: 10.3354/meps12684

Teitelbaum, C. S., \& Mueller, T. (2019). Beyond migration: causes and consequences of nomadic animal movements. Trends in Ecology \& Evolution. doi: 10.1016/j.tree.2019.02.005

Thomson, J. A., Börger, L., Christianen, M. J. A., Esteban, N., Laloë, J.-O., \& Hays, G. C. (2017). 
Implications of location accuracy and data volume for home range estimation and fine-scale movement analysis: comparing Argos and Fastloc-GPS tracking data. Marine Biology, 164(10), 204. doi: $10.1007 / \mathrm{s} 00227-017-3225-7$

Tucker, A. D., MacDonald, B. D., \& Seminoff, J. A. (2014). Foraging site fidelity and stable isotope values of loggerhead turtles tracked in the Gulf of Mexico and northwest Caribbean. Marine Ecology Progress Series, 502, 267-279. doi: 10.3354/meps10655

Vardanis, Y., Nilsson, J.-Å., Klaassen, R. H. G., Strandberg, R., \& Alerstam, T. (2016). Consistency in long-distance bird migration: contrasting patterns in time and space for two raptors. Animal Behaviour, 113, 177-187. doi: 10.1016/j.anbehav.2015.12.014 

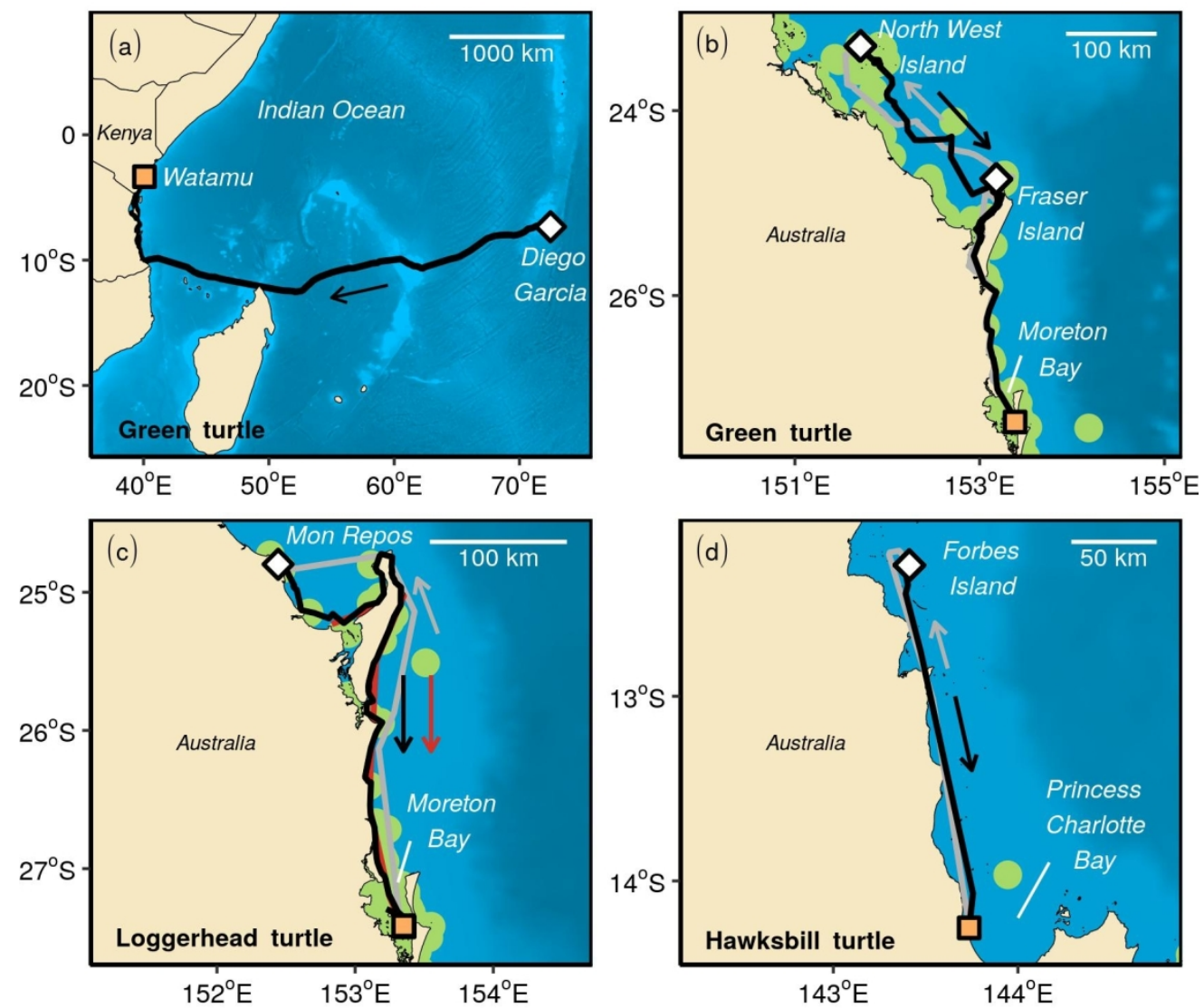

$143 \times 123 \mathrm{~mm}(300 \times 300 \mathrm{DPI})$ 

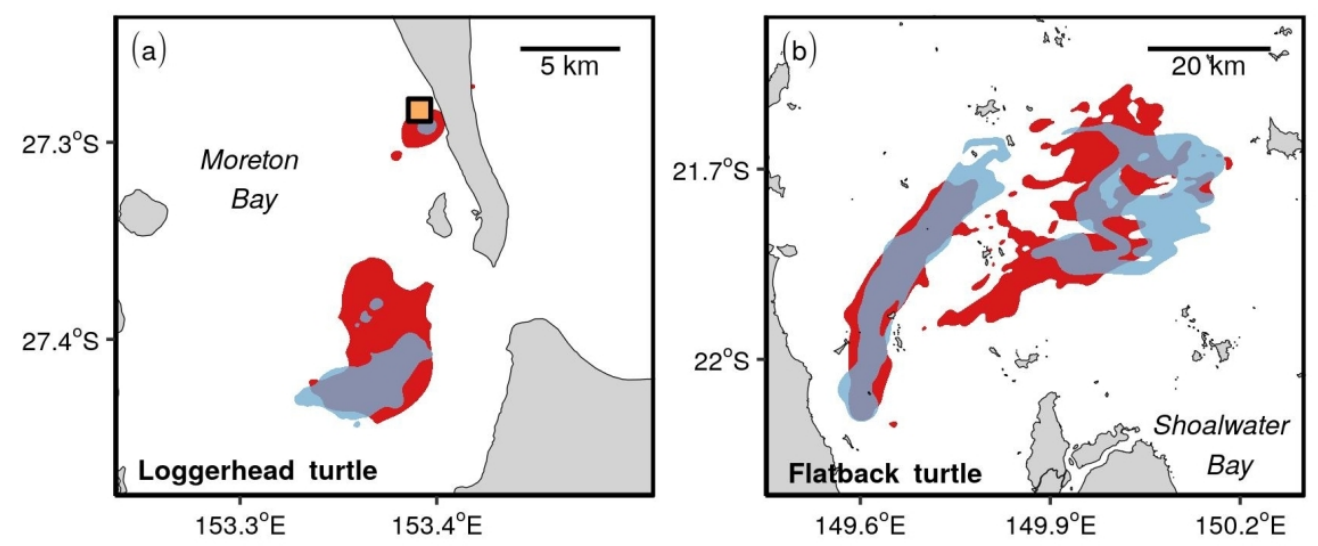

$143 \times 63 \mathrm{~mm}(300 \times 300 \mathrm{DPI})$ 


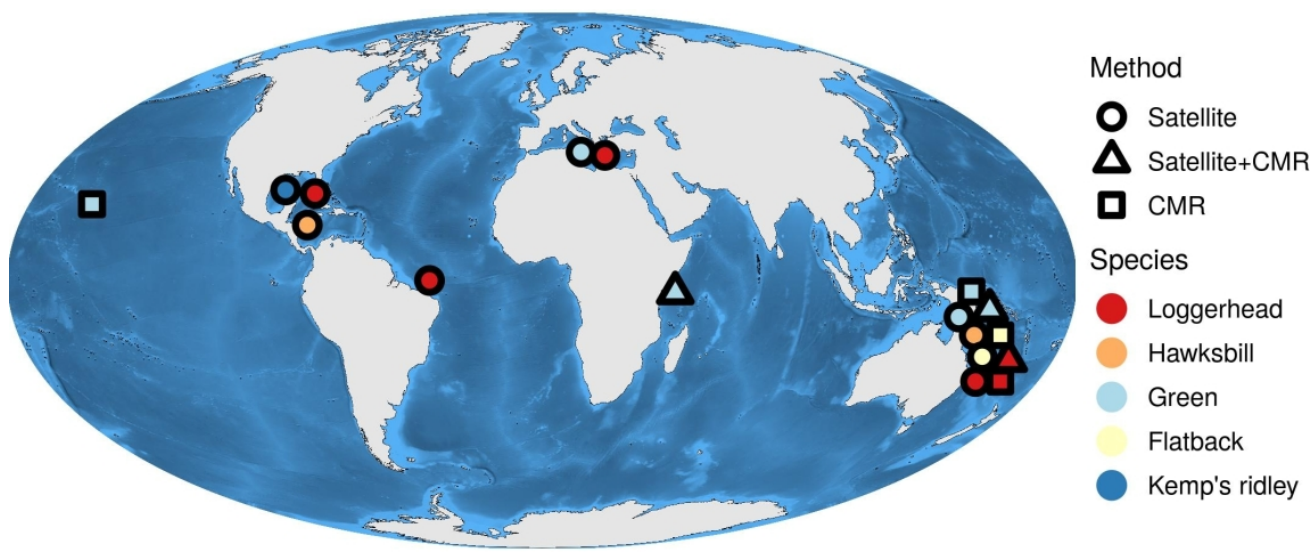

$179 \times 74 \mathrm{~mm}(300 \times 300 \mathrm{DPI})$ 
Supporting Information

Fidelity to foraging sites after long migrations

Takahiro Shimada, Colin Limpus, Mark Hamman, Ian Bell, Nicole Esteban, Rachel Groom, Graeme C. Hays

\section{CONTENTS}

Figure S1 - S5

Table S1 - S2 

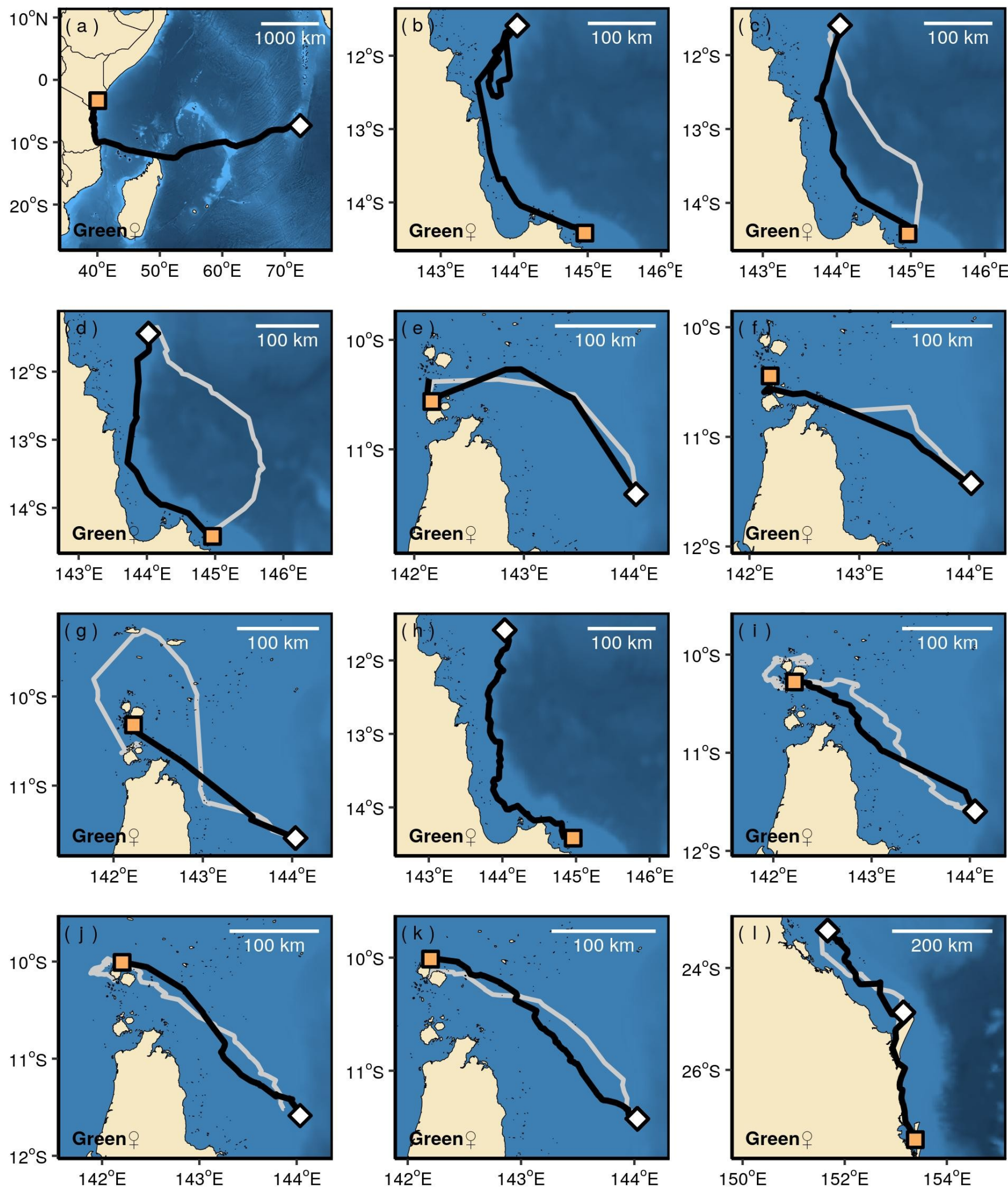

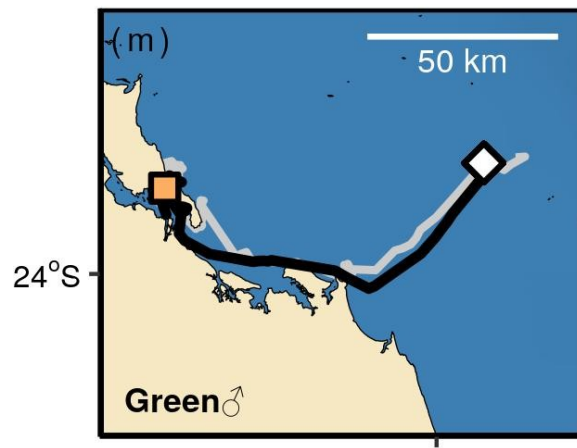

$152^{\circ} \mathrm{E}$

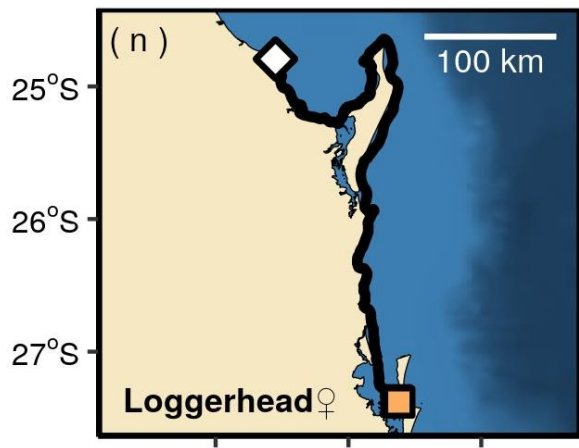

$152^{\circ} \mathrm{E} \quad 153^{\circ} \mathrm{E} \quad 154^{\circ} \mathrm{E}$

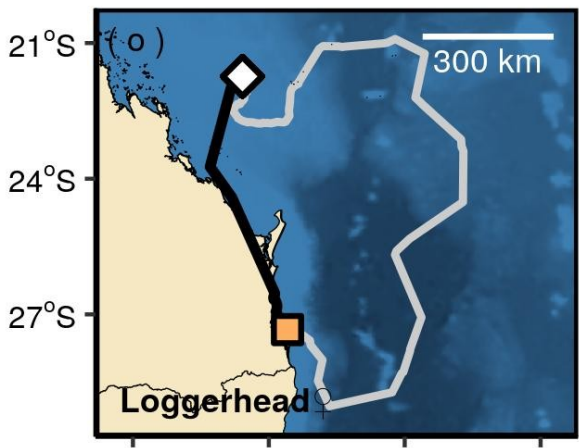

$150^{\circ} \mathrm{E} \quad 153^{\circ} \mathrm{E} \quad 156^{\circ} \mathrm{E} \quad 159^{\circ} \mathrm{E}$ 

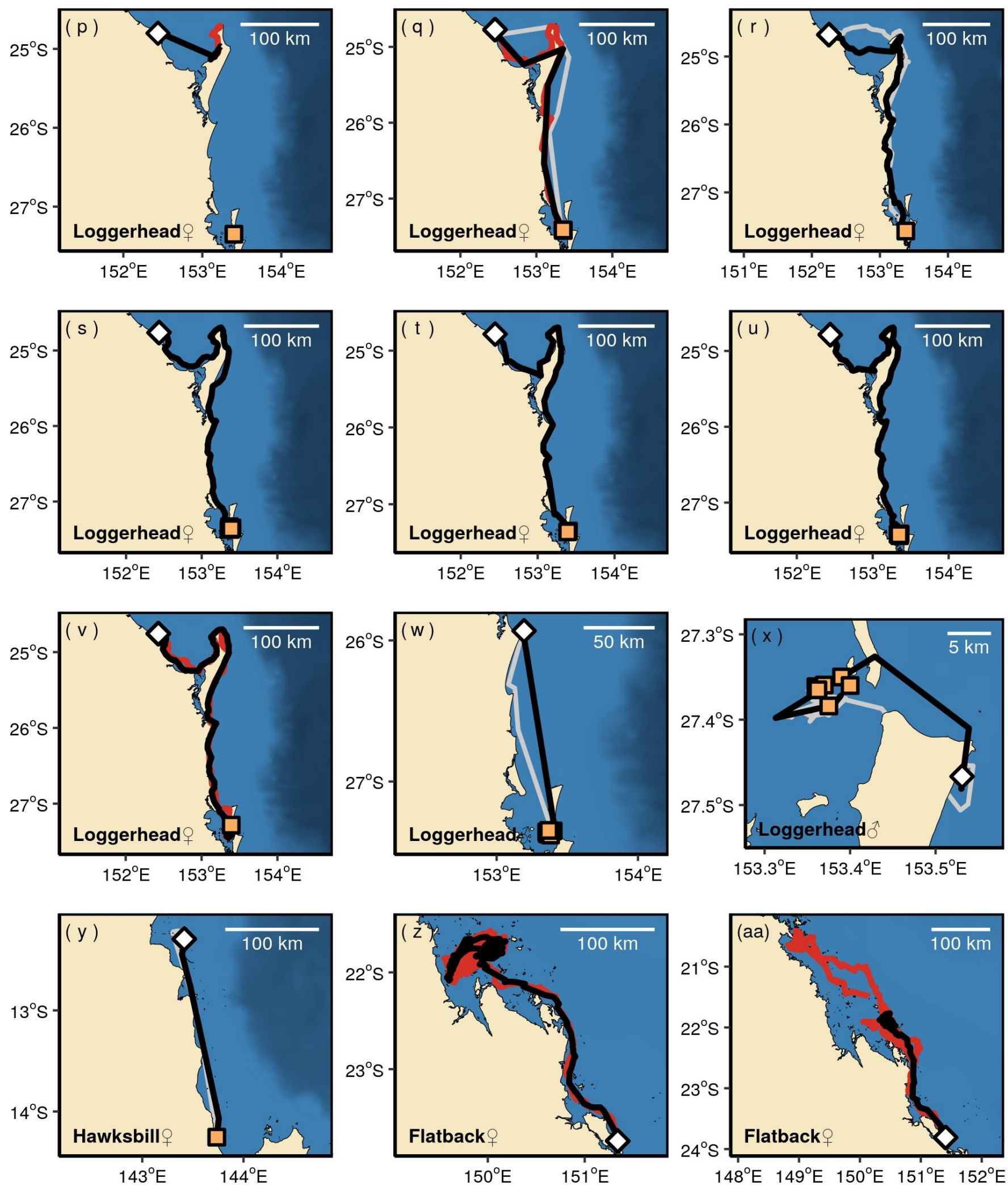

Figure S1 Satellite tracks of 27 turtles showing post-breeding migrations to previously used foraging sites (black line $=1 \mathrm{st}$ time, red line $=2 \mathrm{nd}$ time). For turtles tracked from the foraging grounds, the migration paths to the breeding grounds are also shown (grey line). The symbols denote the nesting beach (white diamond) and the previous capture on foraging site (orange square). The letter of each panel facilitates cross-reference to the data in Table S1. 

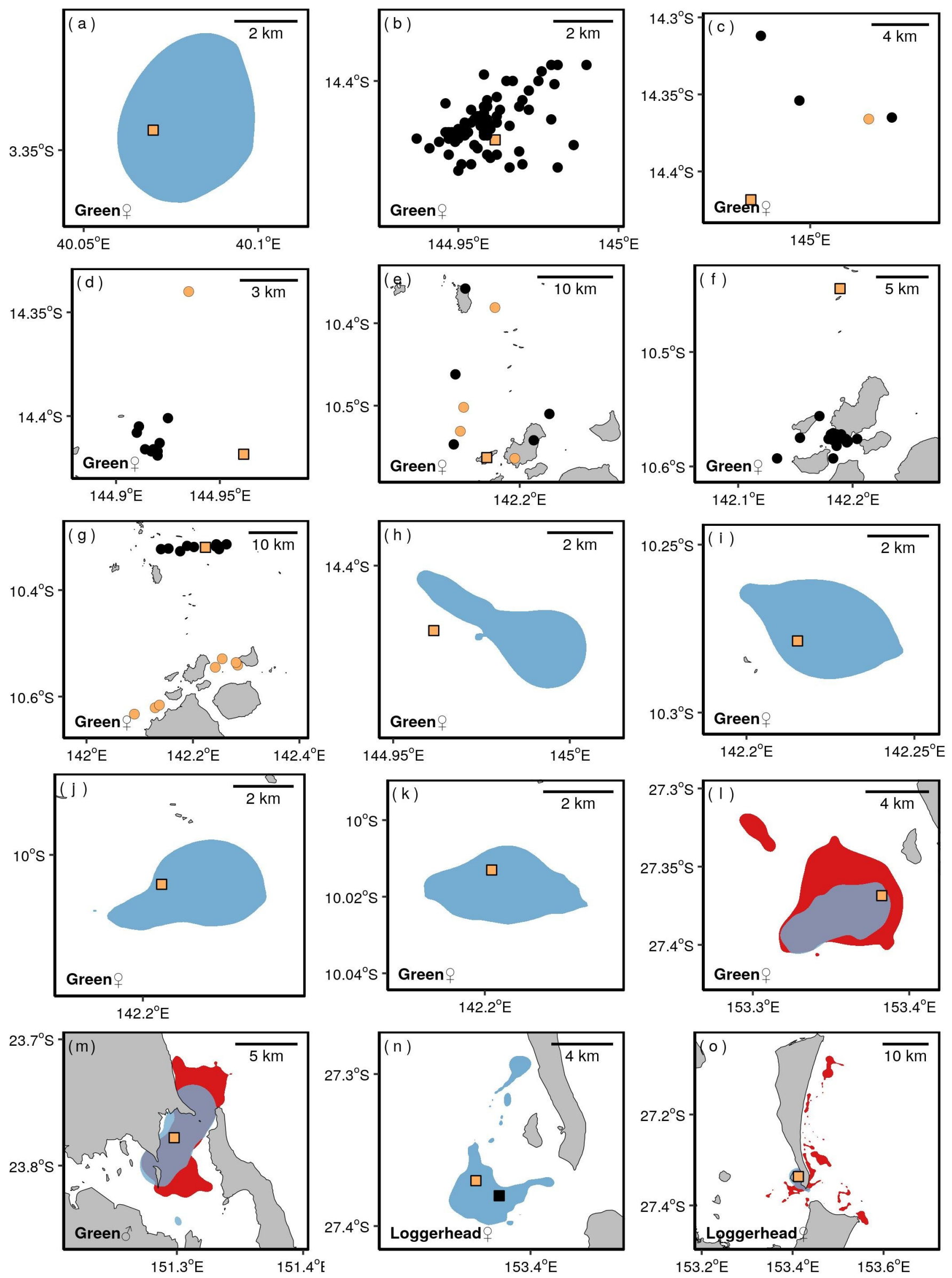

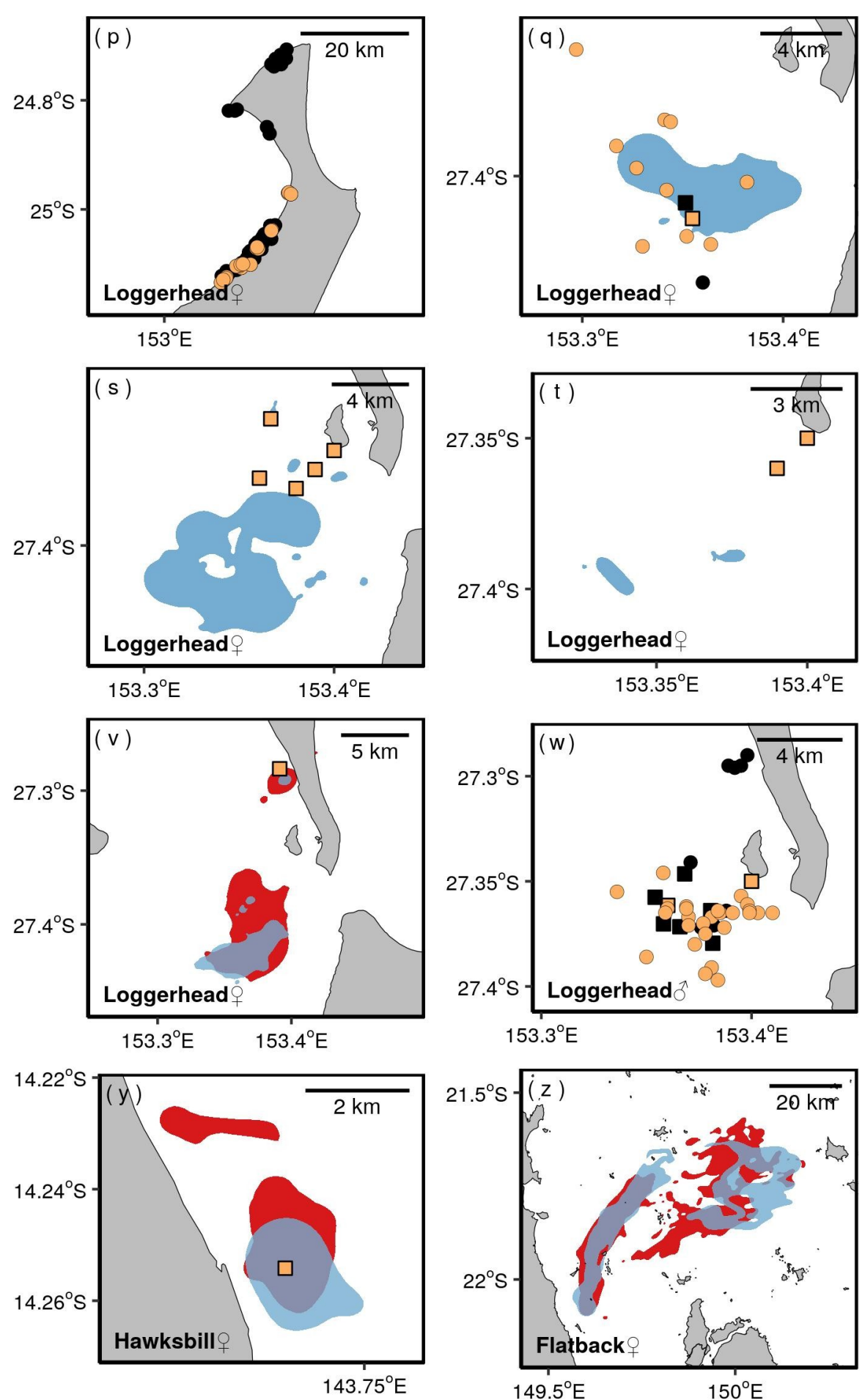
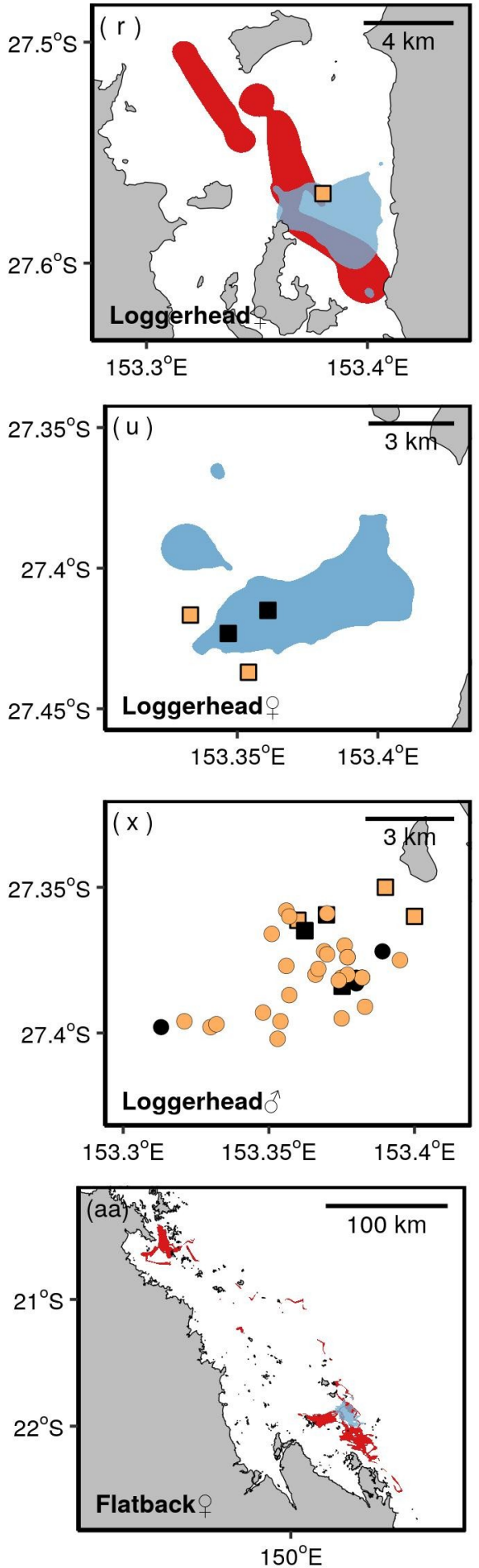

Figure S2 Detailed patterns of space use by 27 sea turtles satellite-tracked to their foraging grounds across years separated by breeding migrations. Home ranges ( $95 \%$ utilisation distributions - polygons) were determined from Fastloc-GPS locations obtained during each tracking occasion; 1 st time $=$ light blue, 2 nd time $=$ red. For turtles tracked with Argos-only tags, high quality fixes (location classes 3, 2,1 - circles) show their locations before (yellow) and after (black) a breeding migration. Squares denote capture locations before (yellow) and after (black) a breeding migration. The letter of each panel facilitates cross-reference to the data in Table S1. We compared the midpoint of the space used in different years. See main text Methods for details. In one of the 27 cases (Figure S2aa), during the second tracking occasion this flatback turtle used two distant foraging sites $>100 \mathrm{~km}$ apart. In this case, to calculate the midpoint of the foraging site, we used the first aggregation of foraging locations prior to its departure to the distant foraging site. 


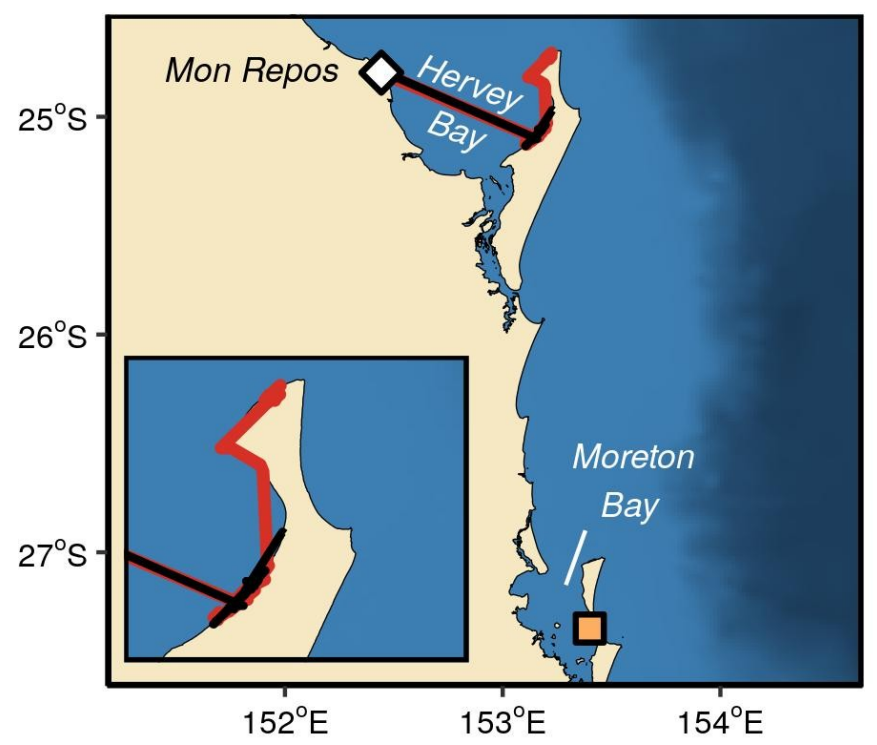

Figure S3 A rare example where a sea turtle shifted its foraging habitats as an adult. This female loggerhead turtle (T1276) was first flipper-tagged at its nesting beach in Mon Repos (white diamond), captured two years later in the Moreton Bay foraging grounds (orange square), and equipped with a satellite tag when it reappeared in Mon Repos to nest 2 and 6 years later (black and red lines respectively). The two separate post-breeding satellite tracks confirmed its residency on the foraging grounds in Hervey Bay, approximately $270 \mathrm{~km}$ from the previous capture on the Moreton Bay foraging grounds. 
Green turtle (Chelonia mydas)
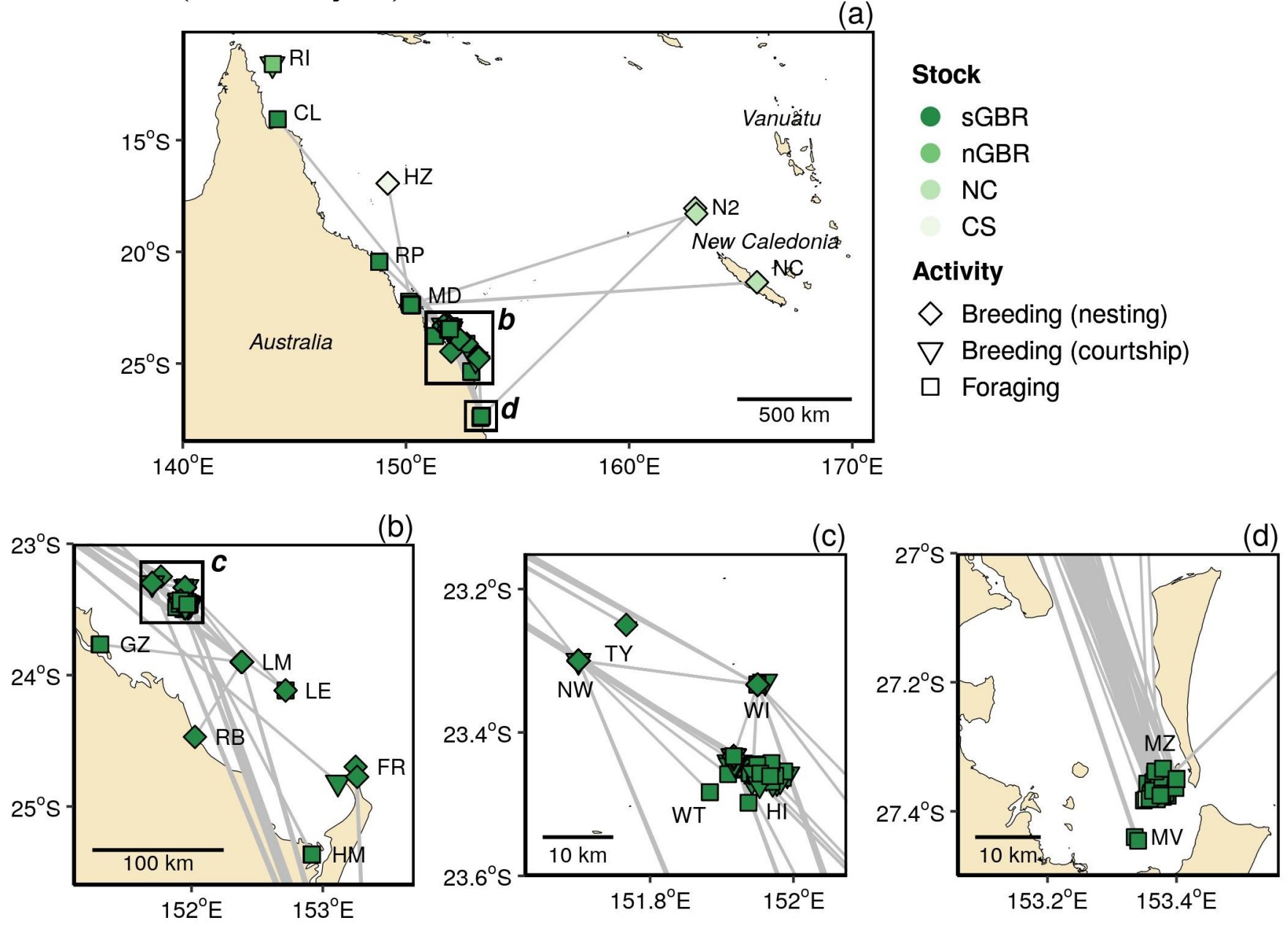

\section{Loggerhead turtle (Caretta caretta)}

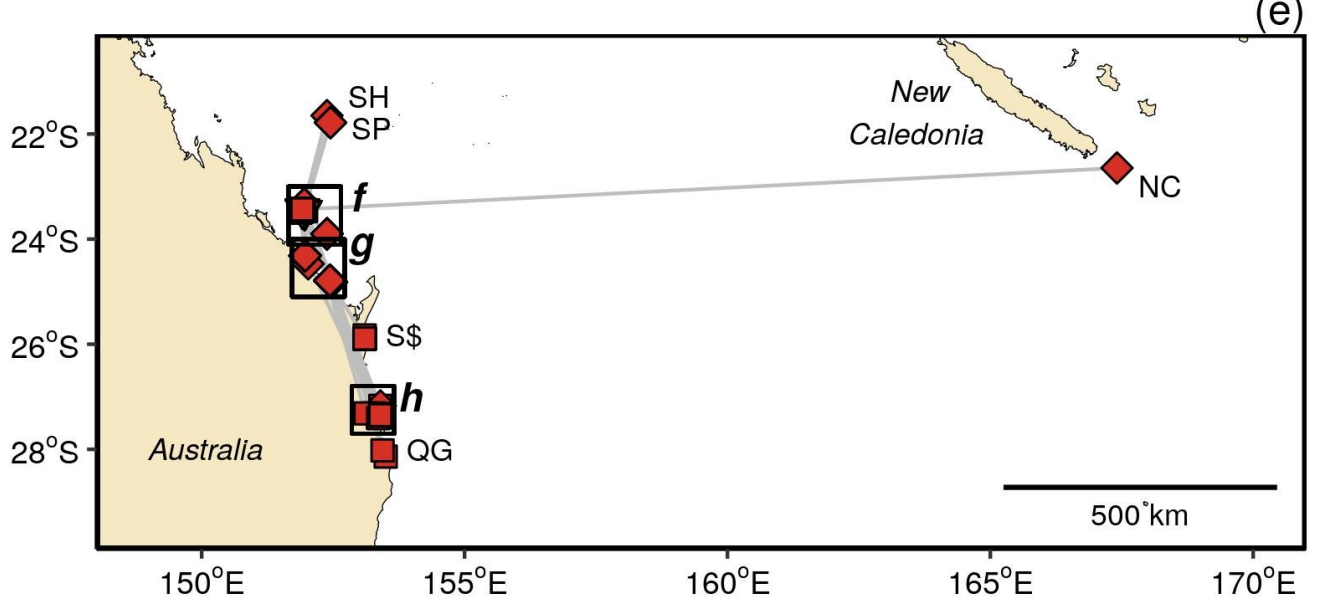

Stock

- sPac

\section{Activity}

$\diamond$ Breeding (nesting)

$\nabla$ Breeding (courtship)

$\square$ Foraging
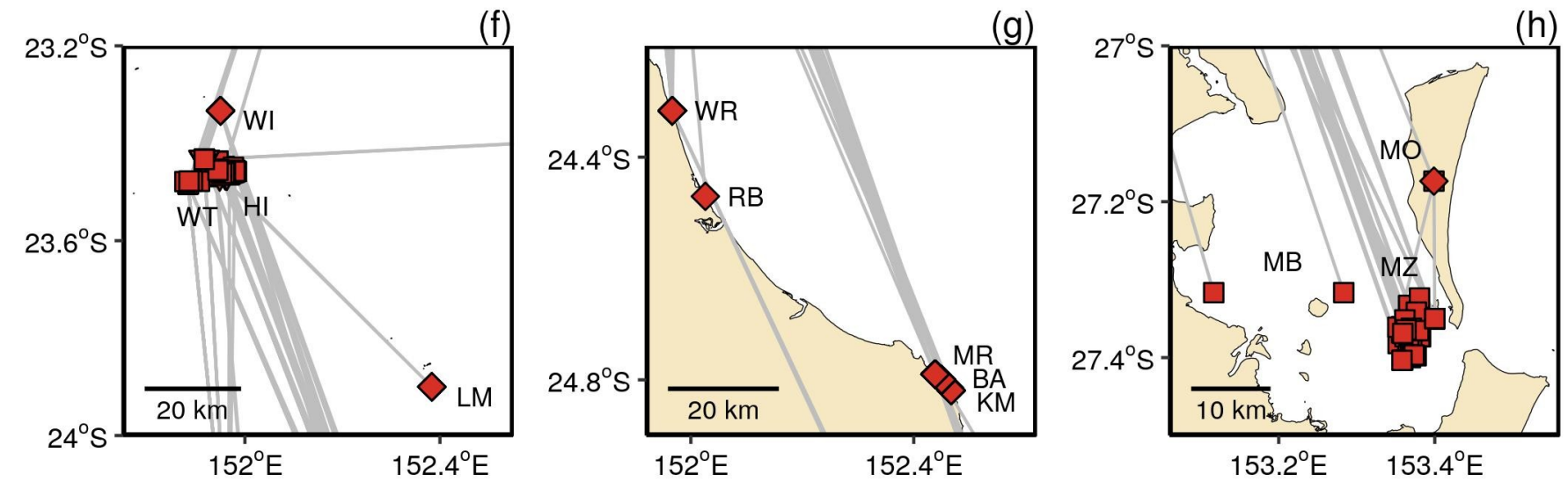


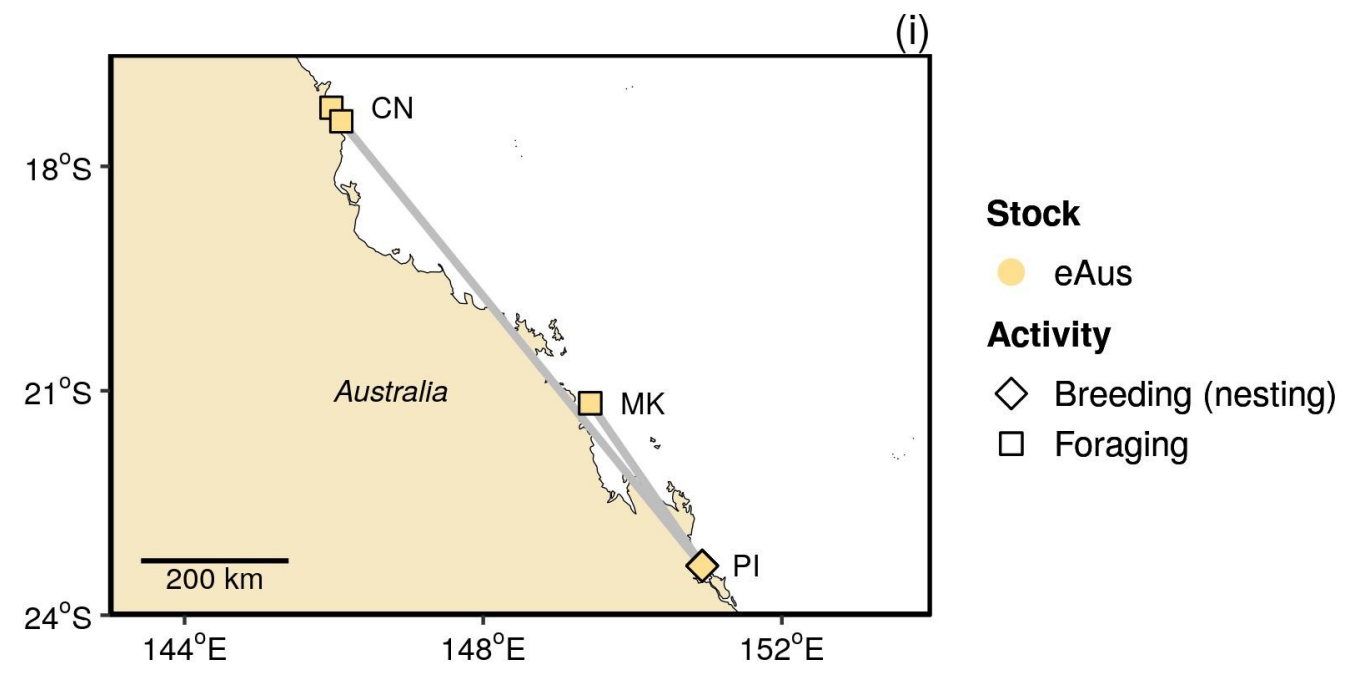

Figure S4 Flipper-tagged turtles ( $\mathrm{n}=175)$ showing post-breeding migrations to previously used foraging sites. (a-d) green turtles, (e-h) loggerhead turtles, (i) flatback turtles. Each point is a capture location on the nesting (diamond), courtship (reverse triangle) or foraging site (square). The lines connect at least three capture locations for each turtle from the foraging to the breeding site and back to the foraging site, and so on. Stock is a genetically distinct population unit of the respective species (sGBR = southern Great Barrier Reef, nGBR = northern Great Barrier Reef, NC $=$ New Caledonia, $\mathrm{CS}=$ Coral Sea, $\mathrm{sPac}=$ South Pacific, eAus $=$ eastern Australia $)$. 

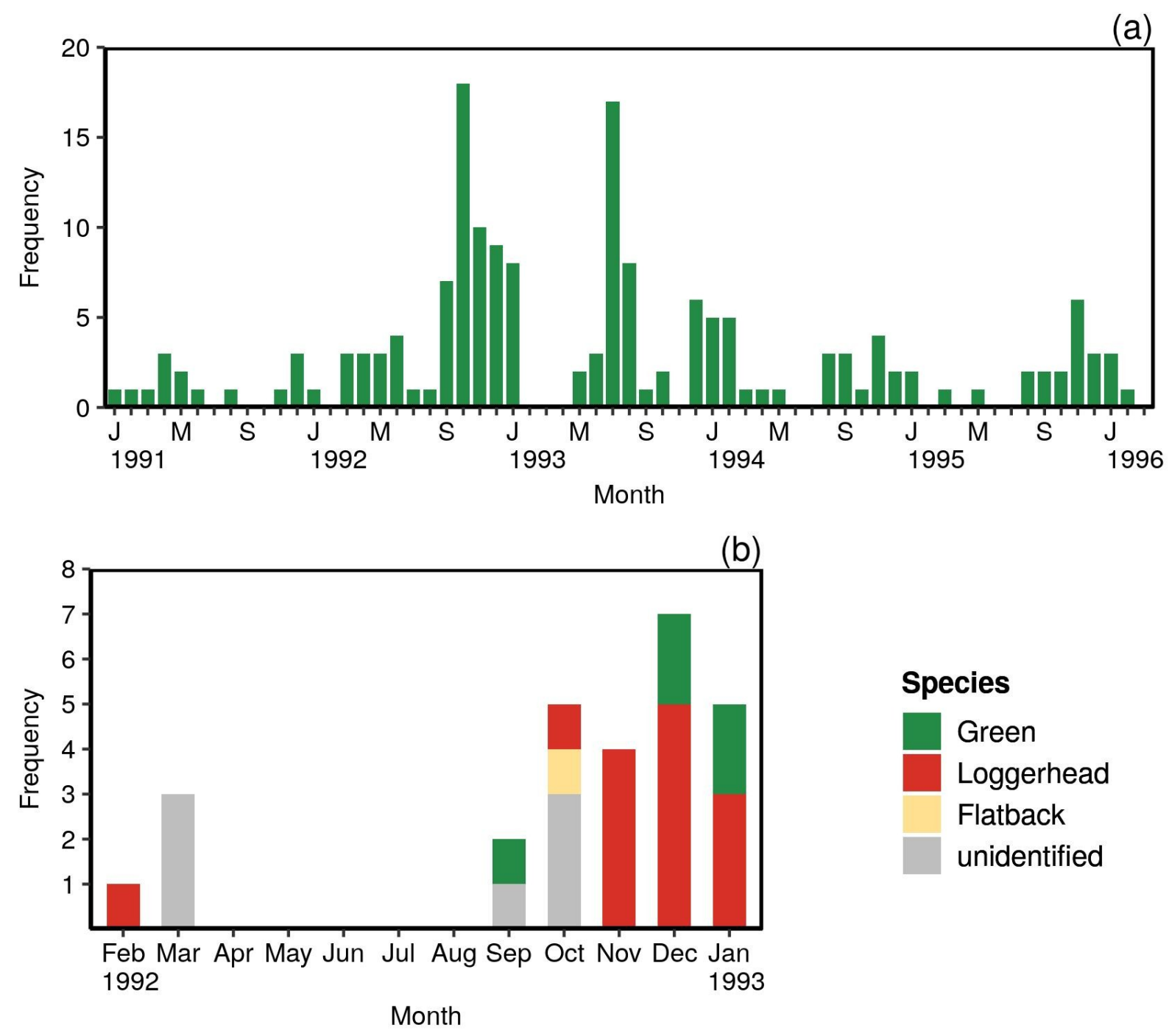

Figure S5 Monthly frequency of stranded sick/dead turtles before and after two floods and a tropical cyclone hit the greater Hervey Bay region in early 1992. (a) Green turtles recorded from the northern Hervey Bay between January 1991 and March 1996 (Queensland Department of Environment and Science, 2018). (b) Multiple sea turtle species recorded in Woongarra Marine Park at the northwest corner of Hervey Bay between February 1992 and January 1993 (modified from Limpus et al. (1993)). 
Table S1 Summary of satellite tracking and capture-mark-recapture data. Stock is defined as a genetically distinct population unit of the respective species (unk = unknown, nGBR = northern Great Barrier Reef, sGBR = southern Great Barrier Reef, $\mathrm{sPac}=$ South Pacific, $\mathrm{nQld}=$ north Queensland, eAus = eastern Australia). Tag is the types of tracking device (GPS = Fastloc-GPS Argos tag, Argos = Argos-only tag). Track days and no. fixes are the number of tracking days and location fixes obtained on the foraging grounds before and/or after a breeding migration. Migration is the sum distance between consecutive location fixes during migration from breeding sites to foraging sites. Min. residency is the number of years between the first and last records on the same foraging sites. Distance between midpoints is the distance between the mid-point of the locations on the foraging site before and after a breeding season (but for T97111 see the caption for Figure S2). Residency estimation method is either multiple satellite tracks (SAT) or a combination of satellite telemetry and capture-mark-recapture using flipper tags (SAT+CMR). Breeding seasons is the number of breeding seasons observed for each turtle between the first and last records on its foraging sites. Letters in the map facilitate cross-reference to the maps in Figure S1 and S2.

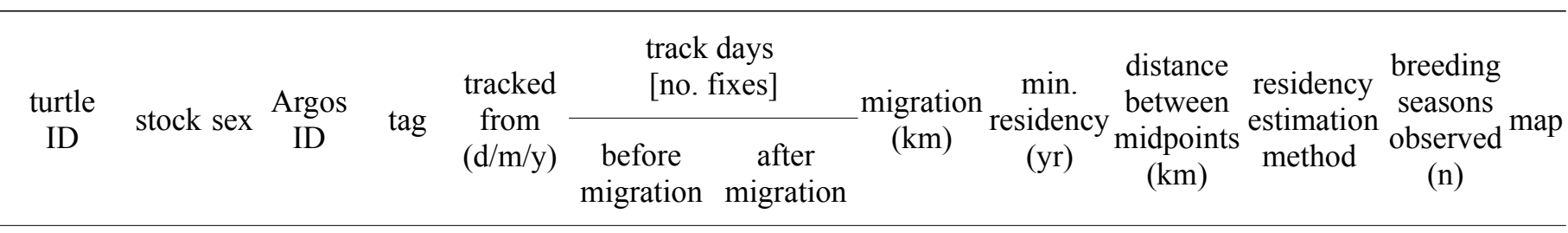

Green turtle (Chelonia mydas)

KE0633 unk F 117570 GPS $^{1}$ 10/8/15

K40735 nGBR F 88365 Argos $^{2} 15 / 11 / 08$

K58178 nGBR F 87898 Argos $^{2}$ 9/9/08

K73295 nGBR F $87899 \operatorname{Argos}^{2}$ 9/9/08

K73662 nGBR F 59963 Argos $^{3} 18 / 10 / 05$

K73728 nGBR F 59965 Argos $^{3}$ 5/10/05

K73740 nGBR F 59966 Argos $^{3} 11 / 10 / 05$

K74859 nGBR F 133763 GPS $^{1}$ 4/11/16

K75275 nGBR F 152622 GPS $^{1} 14 / 10 / 15$

QA20363nGBR F 152623 GPS $^{1} 16 / 10 / 15$

QA20370nGBR F 95895 GPS $^{4} 16 / 10 / 15$

QA11747 sGBR F 48861 GPS $^{4} \quad 15 / 5 / 10$

K93087 sGBR M 96777 GPS $^{4}$ 2/7/10

Loggerhead turtle (Caretta caretta)

$\begin{array}{ccccccc}\text { K22217 } & \text { sPac } & \text { F } & 95892 & \text { GPS }^{4} & 6 / 1 / 10 \\ \text { QA13932 } & \text { sPac } & \text { F } & 95892 & \text { GPS }^{1} & 10 / 4 / 13 & 17 \\ \text { T1276 } & \text { sPac } & \text { F } & 5196 & \text { Argos }^{5} & 2 / 1 / 94 \\ & & & 5196 & \text { Argos }^{5} & 3 / 1 / 99 \\ \text { T14914 } & \text { sPac } & \text { F } & 26040^{\mathrm{a}} & \text { Argos }^{6} & 18 / 9 / 96 & 37 \\ & & & 48847 & \text { GPS }^{4} & 13 / 12 / 10 \\ \text { T23158 } & \text { sPac } & \text { F } & 48850 & \text { GPS }^{4} & 6 / 9 / 10 & 53 \\ \text { T29282 } & \text { sPac } & \text { F } & 88076 & \text { GPS }^{4} & 10 / 12 / 10 \\ \text { T54430 } & \text { sPac } & \text { F } & 48840 & \text { GPS }^{4} & 31 / 12 / 09 \\ \text { T81920 } & \text { sPac } & \text { F } & 48845 & \text { GPS }^{4} & 21 / 12 / 09 \\ \text { T93038 } & \text { sPac } & \text { F } & 48841 & \text { GPS }^{4} & 22 / 12 / 09 \\ & & & 96778 & \text { GPS }^{4} & 20 / 12 / 11 \\ \text { K17100 } & \text { sPac } & \text { M } & 7222 & \text { Argos }^{6} & 30 / 9 / 98 & 42 \\ \text { T53732 } & \text { sPac } & \text { M } & 7224 & \text { Argos }^{6} & 30 / 9 / 98 & 39\end{array}$

Hawksbill turtle (Eretmochelys imbricata)

QA40538 nQld F 140120 GPS $^{1}$ 24/9/14

Flatback turtle (Natator depressus)

T20452 eAus F 96779 GPS $^{4}$ 23/12/09

134194 GPS $^{1} 27 / 11 / 13$

T97111 eAus F $134195^{\mathrm{b}}$ GPS $^{1}$ 26/11/13 $152720^{\mathrm{b}}$ GPS $^{1} \quad 4 / 12 / 15$

$\begin{array}{ccc} & 143[319] & 4810 \\ & 138[67] & 718 \\ 1[1] & 13[3] & 281 \\ 1[1] & 32[10] & 330 \\ 2[4] & 31[5] & 75 \\ & 69[25] & 197 \\ 7[7] & 69[10] & 113 \\ & 34[149] & 449 \\ 8[215] & 119[617] & 232 \\ 5[71] & 128[535] & 215 \\ 1[5] & 133[777] & 260 \\ 58[225] & 62[98] & 577 \\ 80[342] & 86[181] & 116\end{array}$

12.3

1.9

4.5

3.6

0.4

0.5

0.5

10.7

0.7

0.7

0.7

1

0.7

1
1
5
5
3
15
25
3
12
21
12
2
$<1$

$\begin{array}{ll}\text { SAT }+ \text { CMR } & 1 \\ \text { SAT }+ \text { CMR } & 1 \\ \text { SAT }+ \text { CMR } & 1 \\ \text { SAT }+ \text { CMR } & 1 \\ \text { SAT }+ \text { CMR } & 1 \\ \text { SAT }+ \text { CMR } & 1 \\ \text { SAT }+ \text { CMR } & 1 \\ \text { SAT }+ \text { CMR } & 2 \\ \text { SAT }+ \text { CMR } & 1 \\ \text { SAT }+ \text { CMR } & 1 \\ \text { SAT }+ \text { CMR } & 1 \\ \text { SAT }+ \text { CMR } & 2 \\ \text { SAT }+ \text { CMR } & 1\end{array}$

(a)

(b)

(c)

(d)

(e)

(f)

(g)

(h)

(i)

$\begin{array}{rr}113[494] & 520 \\ 77[1037] 434[243] & 647\end{array}$

11

2

7

72 [24]

100

64 [134]

83

$37[10] \quad 1[1] \quad 303$

$1000[750] \quad 462$

7

17.1

17.1

1.1

16.7

19.7

22.4

15.5

15.5

8

27.5

$\begin{array}{lcc}1 & \mathrm{SAT}+\mathrm{CMR} & 3 \\ 3 & \mathrm{SAT}+\mathrm{CMR} & 1 \\ 8 & \mathrm{SAT} & 3\end{array}$

(n)

2

$\mathrm{SAT}+\mathrm{CMR}$

(q)

$1 \mathrm{SAT}+\mathrm{CMR}$

(r)

427 [627] 509

$231[1201] \quad 527$

105 [1208] 488

281 [653] 502

$42[26] \quad 38[8] \quad 151$

39 [26]

36 [5]

14

15 [88]

151 [127]

201

0.7

SAT +CMR

$\mathrm{SAT}+\mathrm{CMR}$

SAT + CMR

$\mathrm{SAT}+\mathrm{CMR}$

(s)

(t)

(u)

(v)

3 SAT + CMR

(w)

$<1$

SAT + CMR

(x)

(y)

$\begin{array}{cc}544[1314] & 382 \\ 39[212] & 300 \\ 35[345] & 230 \\ 257[1368] & 338\end{array}$

$\begin{array}{llll}4.1 & 11 & \text { SAT } & 2 \\ 2.8 & 12 & \text { SAT } & 1\end{array}$

${ }^{1}$ SPLASH10, Wildlife Computers, Seattle, Washington. ${ }^{4}$ F4G, Sirtrack, Hawkes Bay, New Zealand.

${ }^{2}$ SPOT-244A, Wildlife Computers, Seattle, Washington.

${ }^{5} \mathrm{ST} 3$, Telonics, Mesa, Arizona.

${ }^{3}$ KiwiSat1, Sirtrack, Hawkes Bay, New Zealand.

${ }^{6} \mathrm{ST} 14$, Telonics, Mesa, Arizona.

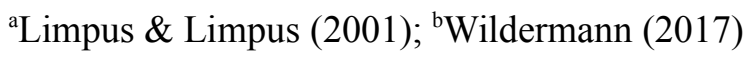


Table S2 Summary of flipper-tagged turtles in SW Pacific, which were recorded on the foraging sites and later successively sighted on the breeding and foraging sites. Stock is a genetically distinct population unit of the respective species $(\mathrm{sGBR}=$ southern Great Barrier Reef, $\mathrm{nGBR}=$ northern Great Barrier Reef, NC $=$ New Caledonia, $\mathrm{CS}=\mathrm{Coral}$ Sea, $\mathrm{sPac}=$ South Pacific, eAus = eastern Australia). See Figure S4 for the site locations. Min. residency is the number of years past between the first and last capture records on the same foraging sites. Spread is the maximum distance between capture locations on the foraging sites. No. seasons is the number of breeding seasons observed for each turtle between the first and last records on its foraging sites. Min. migration is the straight line distance between its breeding and foraging sites. Data of a turtle that had been published previously is marked with the relevant citation and presented here with the most updated information as of 27 December 2018 (Queensland Environmental Protection Agency, 2018).

\begin{tabular}{|c|c|c|c|c|c|c|c|c|c|c|c|c|c|}
\hline \multirow{3}{*}{$\begin{array}{l}\text { turtle } \\
\text { ID }\end{array}$} & \multirow{3}{*}{ stock } & \multirow{3}{*}{ sex } & \multicolumn{8}{|c|}{ foraging } & \multicolumn{3}{|c|}{ breeding } \\
\hline & & & \multirow[b]{2}{*}{ site } & \multicolumn{2}{|c|}{ first record } & \multicolumn{2}{|c|}{ last record } & \multirow{2}{*}{$\begin{array}{l}\text { no. } \\
\text { capture }\end{array}$} & \multirow{2}{*}{$\begin{array}{l}\min . \\
\text { residency } \\
\quad(\mathrm{yr})\end{array}$} & \multirow{2}{*}{$\begin{array}{c}\text { spread } \\
(\mathrm{km})\end{array}$} & \multirow[b]{2}{*}{ site } & \multirow{2}{*}{$\begin{array}{c}\text { no. } \\
\text { seasons }\end{array}$} & \multirow{2}{*}{$\begin{array}{c}\text { min. } \\
\text { migration } \\
(\mathrm{km})\end{array}$} \\
\hline & & & & $\begin{array}{c}\text { date } \\
(\mathrm{d} / \mathrm{m} / \mathrm{y})\end{array}$ & $\begin{array}{l}\mathrm{CCL} \\
(\mathrm{cm})\end{array}$ & $\begin{array}{c}\text { date } \\
(\mathrm{d} / \mathrm{m} / \mathrm{y})\end{array}$ & $\begin{array}{l}\mathrm{CCL} \\
(\mathrm{cm})\end{array}$ & & & & & & \\
\hline \multicolumn{14}{|c|}{ Green turtle (Chelonia mydas) } \\
\hline K1207 & sGBR & $\mathrm{F}$ & $\mathrm{MZ}$ & 19/4/97 & 105.5 & $22 / 5 / 11$ & 106.1 & 2 & 14.1 & $<1$ & WI & 1 & 468 \\
\hline K7573 & sGBR & F & MD & $12 / 7 / 97$ & 105.0 & $2 / 7 / 05$ & 104.7 & 2 & 8 & 4 & LM & 1 & 277 \\
\hline K8514 & sGBR & $\mathrm{F}$ & MD & $13 / 7 / 97$ & 110.1 & 7/7/07 & 109.5 & 2 & 10 & 9 & $\mathrm{HI}$ & 1 & 213 \\
\hline K8543 & sGBR & $\mathrm{F}$ & MD & $6 / 7 / 97$ & 99.5 & $26 / 6 / 12$ & 99.3 & 2 & 15 & 1 & NW & 1 & 186 \\
\hline K8576 & sGBR & $\mathrm{F}$ & MD & $8 / 7 / 97$ & 95.4 & $3 / 7 / 04$ & 95.2 & 2 & 7 & 1 & LM & 1 & 282 \\
\hline K8630 & sGBR & $\mathrm{F}$ & MD & 9/7/97 & 95.1 & 7/7/05 & 96.2 & 2 & 8 & 1 & NW & 1 & 186 \\
\hline K12490 & sGBR & $\mathrm{F}$ & MZ & 19/9/98 & 102.6 & $6 / 11 / 16$ & 106.6 & 2 & 18.1 & 2 & NW & 1 & 482 \\
\hline K17065 & sGBR & $\mathrm{F}$ & $\mathrm{MZ}$ & $15 / 6 / 98$ & 106.8 & $22 / 5 / 11$ & 109.0 & 2 & 12.9 & 6 & HI & 2 & 461 \\
\hline K18511 & sGBR & F & $\mathrm{HM}$ & $14 / 4 / 06$ & 100.2 & $23 / 9 / 08$ & 100.8 & 3 & 2.4 & $<1$ & $\mathrm{HI}$ & 1 & 237 \\
\hline K18629 & sGBR & $\mathrm{F}$ & HM & $7 / 8 / 07$ & 97.9 & $4 / 12 / 11$ & 97.9 & 36 & 4.3 & $<1$ & $\mathrm{HI}$ & 1 & 237 \\
\hline K22954 & sGBR & F & WI & $29 / 12 / 98$ & 101.7 & $21 / 12 / 00$ & 102.0 & 2 & 2 & $<1$ & WI & 1 & $<10$ \\
\hline K25703 & sGBR & F & MZ & 7/2/99 & 109.6 & $14 / 4 / 17$ & 112.8 & 2 & 18.2 & 2 & NW & 1 & 481 \\
\hline K25713 & sGBR & F & MZ & 7/2/99 & 114.3 & 4/11/08 & 114.6 & 2 & 9.7 & 2 & NW & 1 & 480 \\
\hline K29972 & sGBR & $\mathrm{F}$ & HM & $23 / 4 / 10$ & 103.2 & $15 / 2 / 11$ & 103.1 & 22 & 0.8 & $<1$ & HI & 1 & 237 \\
\hline K34519 & sGBR & $\mathrm{F}$ & MZ & $15 / 5 / 00$ & 106.2 & $18 / 5 / 12$ & 106.3 & 3 & 12 & 2 & LM & 1 & 397 \\
\hline K35099 & sGBR & F & MV & $12 / 11 / 01$ & 104.2 & 15/11/10 & 105.2 & 2 & 9 & 1 & WI & 1 & 477 \\
\hline K36347 & sGBR & $\mathrm{F}$ & MZ & 12/11/01 & 116.2 & 25/10/08 & 115.7 & 2 & 7 & 2 & WI & 1 & 470 \\
\hline K36889 & sGBR & $\mathrm{F}$ & MD & $26 / 7 / 00$ & 97.7 & $27 / 6 / 12$ & 102.4 & 2 & 11.9 & $<1$ & WI & 1 & 210 \\
\hline K43396 & sGBR & $\mathrm{F}$ & MD & 6/8/01 & 104.5 & $26 / 6 / 16$ & 101.2 & 4 & 14.9 & 2 & HI & 1 & 214 \\
\hline K49663 & sGBR & $\mathrm{F}$ & MD & 28/6/02 & 93.1 & $25 / 6 / 08$ & 92.9 & 2 & 6 & $<1$ & WI & 1 & 203 \\
\hline K55740 & sGBR & $\mathrm{F}$ & MD & 29/6/03 & 97.2 & 2/7/12 & 97.3 & 2 & 9 & $<1$ & WI & 1 & 211 \\
\hline K56181 & sGBR & F & MD & $11 / 7 / 03$ & 110.4 & $30 / 6 / 06$ & 109.7 & 2 & 3 & 1 & WI & 1 & 206 \\
\hline K64707 & sGBR & F & $\mathrm{MZ}$ & $8 / 4 / 05$ & 117.8 & $26 / 7 / 15$ & 118.4 & 3 & 10.3 & 2 & LM & 1 & 396 \\
\hline K85622 & sGBR & F & $\mathrm{MZ}$ & $19 / 6 / 13$ & 111.3 & $3 / 9 / 17$ & 111.0 & 2 & 4.2 & 1 & LM & 1 & 397 \\
\hline K87252 & sGBR & $\mathrm{F}$ & HM & $25 / 4 / 07$ & 108.9 & $27 / 4 / 11$ & 108.5 & 16 & 4 & $<1$ & $\mathrm{HI}$ & 1 & 237 \\
\hline QA34792 & sGBR & $\mathrm{F}$ & GZ & $1 / 5 / 13$ & 101.1 & $6 / 11 / 17$ & 101.3 & 2 & 4.5 & 1 & LM & 1 & 111 \\
\hline T4746 & sGBR & $\mathrm{F}$ & HI & $7 / 5 / 84$ & 91.5 & 20/8/97 & 93.3 & 3 & 13.3 & 4 & NW & 1 & 30 \\
\hline $\mathrm{T} 12544^{\mathrm{f}}$ & sGBR & $\mathrm{F}$ & MD & $4 / 7 / 87$ & 92.0 & 29/7/00 & 96.4 & 3 & 13.1 & 3 & $\mathrm{HI}$ & 1 & 214 \\
\hline T13634 & sGBR & $\mathrm{F}$ & LE & $14 / 12 / 03$ & & $2 / 12 / 11$ & & 2 & 8 & $<1$ & WI & 2 & 117 \\
\hline T13971 & sGBR & $\mathrm{F}$ & $\mathrm{HI}$ & 3/4/92 & 102.5 & 18/8/99 & 102.5 & 3 & 7.4 & 5 & HI,NW,WI & 1 & 32 \\
\hline T15348 & sGBR & F & HI & $25 / 7 / 85$ & 105.5 & 1/8/98 & 106.1 & 4 & 13 & 4 & WI & 1 & 14 \\
\hline T16397 & sGBR & F & $\mathrm{HI}$ & $10 / 11 / 85$ & 96.0 & 20/8/99 & 104.4 & 7 & 13.8 & 5 & HI,NW & 1 & 32 \\
\hline T18269 & sGBR & F & MD & 4/7/87 & 111.0 & $22 / 6 / 08$ & 110.8 & 2 & 21 & 3 & NW & 2 & 188 \\
\hline T18445 & sGBR & F & MD & 4/7/87 & 112.0 & 7/7/90 & 112.0 & 2 & 3 & $<1$ & NW & 1 & 188 \\
\hline T21110 & sGBR & F & HI & 25/3/87 & & 24/8/99 & 94.0 & 5 & 12.4 & 6 & NW & 1 & 33 \\
\hline $\mathrm{T} 21232^{\mathrm{f}}$ & sGBR & $\mathrm{F}$ & MD & $11 / 7 / 87$ & 107.5 & $26 / 6 / 16$ & 108.5 & 5 & 29 & 3 & TY & 1 & 190 \\
\hline T23103 & sGBR & $\mathrm{F}$ & MD & $6 / 7 / 88$ & 104.0 & $11 / 7 / 90$ & 103.0 & 2 & 2 & $<1$ & LM & 1 & 283 \\
\hline $\mathrm{T} 23481$ & sGBR & F & $\mathrm{RP}$ & $22 / 6 / 88$ & 115.0 & $17 / 8 / 91$ & 114.2 & 5 & 3.2 & $<1$ & LM & 1 & 531 \\
\hline T23598 & sGBR & F & $\mathrm{MZ}$ & $23 / 3 / 97$ & 108.2 & $22 / 4 / 12$ & 109.1 & 3 & 15.1 & 2 & $\mathrm{HI}$ & 2 & 459 \\
\hline T23600 & sGBR & $\mathrm{F}$ & HI & $3 / 4 / 90$ & 101.0 & 23/8/99 & 101.5 & 2 & 9.4 & 7 & HI & 1 & $<10$ \\
\hline $\mathrm{T} 25882^{\mathrm{f}}$ & sGBR & $\mathrm{F}$ & MD & $10 / 7 / 89$ & 101.5 & $28 / 6 / 04$ & 101.2 & 3 & 15 & 1 & HI & 1 & 215 \\
\hline $\mathrm{T} 29785^{\mathrm{f}}$ & sGBR & $\mathrm{F}$ & MD & $17 / 7 / 87$ & 102.0 & $3 / 7 / 03$ & 102.4 & 3 & 16 & 3 & NW & 1 & 188 \\
\hline T31419f & sGBR & $\mathrm{F}$ & MD & $4 / 7 / 88$ & 114.0 & 2/7/03 & 114.5 & 2 & 15 & 3 & NW & 1 & 188 \\
\hline T32203 & sGBR & $\mathrm{F}$ & MD & $16 / 7 / 90$ & 97.0 & 7/7/04 & 97.8 & 4 & 14 & 9 & NW & 1 & 188 \\
\hline
\end{tabular}




\begin{tabular}{|c|c|c|c|c|c|c|c|c|c|c|c|c|c|}
\hline T32315 & sGBR & $\mathrm{F}$ & MD & $8 / 7 / 88$ & 115.5 & $15 / 7 / 97$ & 115.5 & 3 & 9 & 3 & NW & 1 & 188 \\
\hline T35025 & sGBR & $\mathrm{F}$ & MZ & $1 / 9 / 90$ & 109.2 & $4 / 2 / 07$ & 111.7 & 5 & 16.4 & 4 & WI & 2 & 469 \\
\hline T35755 & sGBR & F & MD & $16 / 7 / 90$ & 99.4 & $9 / 8 / 01$ & 100.1 & 3 & 11.1 & 8 & HI & 2 & 214 \\
\hline Т36703 & sGBR & F & WI & $23 / 12 / 01$ & 97.6 & $26 / 12 / 15$ & 97.1 & 3 & 14 & $<1$ & WI & 1 & $<10$ \\
\hline T37192 & sGBR & $\mathrm{F}$ & MD & $16 / 7 / 88$ & 99.0 & $6 / 7 / 07$ & 99.6 & 4 & 19 & 6 & LM & 2 & 283 \\
\hline Т37408 & sGBR & $\mathrm{F}$ & $\mathrm{RP}$ & $26 / 7 / 88$ & 109.0 & $18 / 8 / 91$ & 107.4 & 4 & 3.1 & $<1$ & LM & 1 & 531 \\
\hline Т37476 & sGBR & $\mathrm{F}$ & HI & $26 / 3 / 89$ & 105.0 & 23/8/99 & 106.5 & 3 & 10.4 & 7 & LM & 1 & 70 \\
\hline Т38073 & sGBR & $\mathrm{F}$ & HI & $6 / 6 / 89$ & 108.5 & $22 / 10 / 98$ & 109.6 & 2 & 9.4 & 4 & HI & 1 & $<10$ \\
\hline $\mathrm{T} 39721^{\mathrm{f}}$ & sGBR & $\mathrm{F}$ & MD & $13 / 7 / 89$ & 95.0 & $3 / 7 / 06$ & 95.3 & 4 & 17 & 7 & HI,WI & 2 & 214 \\
\hline Т39733 & sGBR & $\mathrm{F}$ & MD & $12 / 7 / 89$ & 111.0 & $14 / 7 / 97$ & 111.3 & 2 & 8 & 6 & WI & 1 & 211 \\
\hline T45501 & sGBR & $\mathrm{F}$ & WI & $30 / 3 / 90$ & 89.0 & $18 / 12 / 03$ & 101.8 & 3 & 13.7 & $<1$ & NW & 1 & 26 \\
\hline T45545 & sGBR & $\mathrm{F}$ & WI & $1 / 4 / 90$ & 102.0 & $29 / 12 / 00$ & 102.6 & 3 & 10.8 & $<1$ & LM & 1 & 77 \\
\hline T45593 & sGBR & $\mathrm{F}$ & HI & $10 / 4 / 90$ & 103.0 & $16 / 8 / 99$ & 102.9 & 6 & 9.4 & 6 & LM & 1 & 70 \\
\hline T45640 & sGBR & $\mathrm{F}$ & HI & 7/4/90 & & $16 / 8 / 99$ & 104.7 & 3 & 9.4 & 5 & HI & 1 & $<10$ \\
\hline $\mathrm{T} 50350^{\mathrm{f}}$ & sGBR & $\mathrm{F}$ & MD & 9/7/90 & 112.5 & $3 / 7 / 04$ & 112.1 & 4 & 14 & 3 & HI & 1 & 215 \\
\hline T50727f & sGBR & $\mathrm{F}$ & MD & $18 / 7 / 90$ & 107.8 & $4 / 8 / 00$ & 107.5 & 4 & 10.1 & 6 & NW & 1 & 188 \\
\hline T50862 & sGBR & $\mathrm{F}$ & MD & $24 / 7 / 90$ & 98.5 & $29 / 6 / 12$ & 98.7 & 4 & 21.9 & 4 & WI & 1 & 211 \\
\hline T50898 & sGBR & $\mathrm{F}$ & $\mathrm{MZ}$ & $19 / 8 / 90$ & 90.5 & $14 / 4 / 17$ & 114.1 & 5 & 26.7 & 4 & HI & 1 & 460 \\
\hline T51048 & sGBR & $\mathrm{F}$ & MZ & 20/9/90 & 88.0 & $20 / 10 / 10$ & 110.1 & 4 & 20.1 & 3 & NW & 1 & 480 \\
\hline T51161 & sGBR & $\mathrm{F}$ & $\mathrm{MZ}$ & $28 / 10 / 90$ & 111.4 & $13 / 5 / 10$ & 114.0 & 3 & 19.6 & 4 & NW & 1 & 482 \\
\hline T51205 & sGBR & $\mathrm{F}$ & MZ & $10 / 11 / 90$ & 83.0 & $1 / 7 / 18$ & 110.1 & 5 & 27.7 & 4 & LM & 2 & 398 \\
\hline Т53794 & sGBR & $\mathrm{F}$ & $\mathrm{MZ}$ & $31 / 8 / 91$ & 87.7 & $28 / 5 / 17$ & 102.4 & 2 & 25.8 & 4 & LM,RB & 3 & 398 \\
\hline Т53796 & sGBR & $\mathrm{F}$ & MZ & $31 / 8 / 91$ & 88.0 & $25 / 10 / 15$ & 106.7 & 4 & 24.2 & 5 & HI & 1 & 461 \\
\hline T55135 & sGBR & $\mathrm{F}$ & MD & 8/7/91 & 97.5 & 6/7/96 & 97.9 & 2 & 5 & 4 & NW & 1 & 188 \\
\hline T55278f & sGBR & $\mathrm{F}$ & MD & 9/7/91 & 110.9 & $7 / 7 / 04$ & 111.1 & 4 & 13 & 8 & HI & 1 & 214 \\
\hline $\mathrm{T} 55280^{\mathrm{f}}$ & sGBR & $\mathrm{F}$ & MD & $18 / 7 / 91$ & 98.7 & $9 / 8 / 01$ & 99.1 & 2 & 10.1 & 8 & LM & 1 & 283 \\
\hline $\mathrm{T} 57107^{\mathrm{f}}$ & sGBR & $\mathrm{F}$ & MD & $16 / 7 / 91$ & 101.3 & $3 / 7 / 12$ & 101.7 & 4 & 21 & 3 & LM & 1 & 283 \\
\hline T57115f & sGBR & $\mathrm{F}$ & MD & $16 / 7 / 91$ & 100.6 & $30 / 6 / 04$ & 101.7 & 2 & 13 & 3 & NW & 1 & 188 \\
\hline $\mathrm{T} 57117^{\mathrm{f}}$ & sGBR & $\mathrm{F}$ & MD & $16 / 7 / 91$ & 107.7 & $10 / 7 / 07$ & 107.4 & 5 & 16 & 3 & WI & 1 & 211 \\
\hline T60727 & sGBR & $\mathrm{F}$ & WI & $30 / 12 / 98$ & 98.2 & $26 / 12 / 00$ & & 2 & 2 & $<1$ & WI & 1 & $<10$ \\
\hline T66988 & sGBR & $\mathrm{F}$ & $\mathrm{MZ}$ & $6 / 6 / 01$ & 106.2 & $24 / 5 / 05$ & 107.0 & 2 & 4 & $<1$ & NW & 1 & 480 \\
\hline T67510 & sGBR & $\mathrm{F}$ & MZ & 7/11/93 & 73.4 & $19 / 6 / 13$ & 105.6 & 4 & 19.6 & 5 & HI & 1 & 460 \\
\hline T69752 & sGBR & $\mathrm{F}$ & MD & 7/7/97 & 91.5 & $29 / 6 / 05$ & 91.4 & 2 & 8 & 1 & NW & 1 & 187 \\
\hline T71572 & sGBR & $\mathrm{F}$ & MZ & $1 / 5 / 93$ & 114.0 & $25 / 4 / 95$ & 113.7 & 2 & 2 & 5 & NW & 1 & 481 \\
\hline T77432 & sGBR & $\mathrm{F}$ & MD & $22 / 7 / 94$ & 112.2 & $22 / 6 / 08$ & 113.1 & 3 & 13.9 & 2 & HI,NW & 1 & 212 \\
\hline $\mathrm{T} 77435^{\mathrm{f}}$ & sGBR & $\mathrm{F}$ & MD & 26/7/94 & 100.5 & $2 / 8 / 00$ & 100.4 & 3 & 6 & 1 & LM & 1 & 277 \\
\hline Т77447 & sGBR & $\mathrm{F}$ & MD & 26/7/94 & 102.0 & $5 / 7 / 10$ & 103.6 & 2 & 16 & 20 & LM & 2 & 296 \\
\hline T77449 & sGBR & $\mathrm{F}$ & MD & $30 / 7 / 94$ & 106.0 & $7 / 7 / 04$ & 106.5 & 2 & 9.9 & $<1$ & NW & 1 & 179 \\
\hline T77513 & sGBR & $\mathrm{F}$ & MD & $23 / 7 / 94$ & 100.5 & 3/7/04 & 101.3 & 2 & 10 & $<1$ & NW & 1 & 186 \\
\hline T77744f & sGBR & $\mathrm{F}$ & MD & 2/8/94 & 109.8 & $31 / 7 / 00$ & 109.8 & 2 & 6 & 1 & LE & 1 & 318 \\
\hline T77846 & sGBR & $\mathrm{F}$ & MD & $1 / 8 / 94$ & 103.3 & $3 / 7 / 05$ & 103.6 & 2 & 10.9 & 1 & WI & 1 & 204 \\
\hline T78396 & sGBR & $\mathrm{F}$ & MD & $8 / 7 / 95$ & 105.7 & 27/6/05 & 106.2 & 2 & 10 & $<1$ & LM & 1 & 282 \\
\hline T79396 & sGBR & $\mathrm{F}$ & MZ & $13 / 8 / 95$ & 105.0 & $18 / 9 / 12$ & 108.1 & 2 & 17.1 & 1 & LM & 2 & 395 \\
\hline T82051 & sGBR & $\mathrm{F}$ & $\mathrm{MZ}$ & $26 / 5 / 96$ & 100.5 & $30 / 3 / 08$ & 111.6 & 4 & 11.9 & 3 & LM & 1 & 397 \\
\hline T82466 & sGBR & $\mathrm{F}$ & MZ & $22 / 10 / 00$ & 113.3 & $27 / 10 / 07$ & 114.4 & 2 & 7 & 2 & FR & 1 & 297 \\
\hline T82542 & sGBR & $\mathrm{F}$ & $\mathrm{MZ}$ & $4 / 10 / 98$ & 112.7 & $14 / 5 / 12$ & 113.2 & 2 & 13.6 & 1 & LM & 2 & 398 \\
\hline T82681 & sGBR & $\mathrm{F}$ & $\mathrm{MZ}$ & $4 / 5 / 98$ & 107.0 & $15 / 11 / 10$ & 110.0 & 2 & 12.5 & 2 & LM & 3 & 396 \\
\hline $\mathrm{T} 83625^{\mathrm{f}}$ & sGBR & $\mathrm{F}$ & MD & 9/7/96 & 96.7 & $5 / 7 / 06$ & 97.7 & 3 & 10 & 3 & LM & 1 & 278 \\
\hline Т84474 & sGBR & $\mathrm{F}$ & $\mathrm{MZ}$ & $24 / 9 / 98$ & 110.5 & $5 / 10 / 15$ & 113.0 & 4 & 17 & 2 & WI & 1 & 470 \\
\hline T87153 & sGBR & $\mathrm{F}$ & HI & $30 / 10 / 95$ & 102.0 & $17 / 10 / 98$ & 102.6 & 3 & 3 & 5 & NW & 1 & 32 \\
\hline Т92590 & sGBR & $\mathrm{F}$ & MV,MZ & $29 / 5 / 96$ & 93.2 & $5 / 10 / 10$ & & 2 & 14.4 & 2 & $\mathrm{HI}$ & 1 & 460 \\
\hline Т93006 & sGBR & $\mathrm{F}$ & $\mathrm{MZ}$ & $30 / 3 / 97$ & 104.5 & $8 / 2 / 07$ & 105.6 & 3 & 9.9 & 4 & WI & 1 & 468 \\
\hline T94461 ${ }^{\mathrm{f}}$ & sGBR & $\mathrm{F}$ & MD & $1 / 7 / 96$ & 101.6 & $3 / 8 / 00$ & 101.5 & 2 & 4.1 & 3 & NW & 1 & 185 \\
\hline X-38000 & sGBR & $\mathrm{F}$ & HI & $15 / 4 / 90$ & 101.0 & $13 / 8 / 97$ & 101.4 & 2 & 7.3 & 6 & NW & 1 & 32 \\
\hline $\mathrm{X} 2625^{\mathrm{d}}$ & sGBR & $\mathrm{F}$ & $\mathrm{HI}$ & $13 / 5 / 76$ & 99.0 & 23/8/99 & 101.9 & 6 & 23.3 & 8 & HI & 1 & $<10$ \\
\hline$X 9071^{d}$ & sGBR & $\mathrm{F}$ & HI & $3 / 6 / 78$ & & $22 / 10 / 96$ & 101.7 & 5 & 18.4 & 6 & HI & 2 & $<10$ \\
\hline X14662 & sGBR & $\mathrm{F}$ & $\mathrm{MZ}$ & 23/9/90 & 117.6 & $13 / 5 / 10$ & 119.1 & 2 & 19.6 & 4 & LM & 3 & 398 \\
\hline X15110 & sGBR & $\mathrm{F}$ & $\mathrm{HI}$ & $3 / 11 / 81$ & 102.5 & $22 / 10 / 98$ & 104.2 & 5 & 17 & 5 & LM & 1 & 70 \\
\hline$X 22178^{d}$ & sGBR & $\mathrm{F}$ & HI & $18 / 5 / 80$ & 106.0 & $22 / 10 / 99$ & 106.4 & 7 & 19.4 & 4 & $\mathrm{HI}$ & 1 & $<10$ \\
\hline X37792 & sGBR & $\mathrm{F}$ & WT & $15 / 2 / 85$ & 103.0 & $12 / 8 / 96$ & 103.5 & 3 & 11.5 & 4 & NW & 1 & 28 \\
\hline X38371 & sGBR & $\mathrm{F}$ & $\mathrm{HI}$ & $12 / 10 / 81$ & 89.5 & $15 / 10 / 94$ & 99.1 & 4 & 13 & 5 & LM & 1 & 70 \\
\hline K15008 & sGBR & M & WI & $24 / 12 / 97$ & 98.4 & $26 / 12 / 15$ & 98.5 & 5 & 18 & $<1$ & WI & 1 & $<10$ \\
\hline K39096 & sGBR & M & WI & $26 / 12 / 00$ & 95.6 & $18 / 12 / 02$ & 95.4 & 2 & 2 & $<1$ & NW & 1 & 26 \\
\hline
\end{tabular}


T1083 sGBR M T4286 sGBR M T4685 sGBR M T12111 sGBR M T15700 sGBR M T16544 sGBR M T31049 sGBR M T45292 sGBR M T45365 sGBR M T56258 sGBR M T58597 sGBR M T60994 sGBR M T78307 ${ }^{f}$ sGBR M T92541 sGBR M X9049 sGBR M X13768 sGBR M X22050 sGBR M X38260 sGBR M X38458 sGBR M X38561 sGBR M K24035 nGBR M K25986 NC F K43255: NC F T77864f NC F T85488 ${ }^{\mathrm{f}}$ NC $\mathrm{F}$ $\mathrm{T} 43428$ CS F X37735 CS F $\begin{array}{lllll}\text { HI } & 25 / 2 / 84 & 89.5 & 26 / 10 / 99 & 96.1\end{array}$

HI $\quad 11 / 5 / 84 \quad 95.0 \quad 17 / 8 / 99 \quad 95.2 \quad 4$

HI $\quad 7 / 7 / 85 \quad 100.5 \quad 31 / 7 / 98 \quad 102.8 \quad 3$

$\begin{array}{lllll}\text { HI } & 29 / 10 / 94 & 93.4 & 25 / 10 / 98 & 93.5\end{array}$

HI $\quad 13 / 3 / 87 \quad 106.021 / 10 / 98$

$\begin{array}{lllll}\text { HI } & 23 / 3 / 88 & 86.0 & 20 / 8 / 99 & 87.7\end{array}$

HI $\quad 19 / 3 / 90 \quad 92.0 \quad 25 / 10 / 98 \quad 93.0$

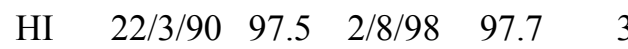

HI $\quad 1 / 4 / 91 \quad 105.223 / 10 / 98 \quad 105.0 \quad 6$

HI $\quad 29 / 3 / 92 \quad 93.3 \quad 22 / 10 / 95$

$\begin{array}{llllll}\text { HI } & 30 / 3 / 92 & 97.7 & 18 / 8 / 97 & 97.8 & 2\end{array}$

$\begin{array}{llllll}\text { MD } & 12 / 7 / 95 & 92.8 & 6 / 7 / 04 & 93.9 & 2\end{array}$

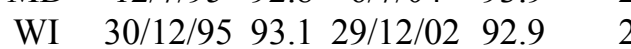

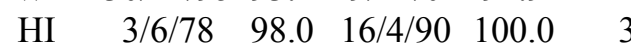

$\begin{array}{lllll}\text { HI } & 29 / 10 / 78 & 103.5 & 21 / 7 / 89 & 103.5\end{array}$

HI $\quad 31 / 1 / 80 \quad 105.5 \quad 19 / 8 / 99$

$\begin{array}{lllll}\text { HI } & 27 / 8 / 85 & 95.0 & 22 / 8 / 99 & 96.0\end{array}$

HI $\quad 13 / 10 / 81 \quad 92.0 \quad 14 / 8 / 99 \quad 93.5$

$\begin{array}{llll}\text { HI } & 4 / 11 / 81 & 9 / 4 / 90 & 108.5\end{array}$

$\begin{array}{llllll}\text { RI } & 5 / 8 / 02 & 90.5 & 2 / 12 / 05 & 90.4 & 3\end{array}$

$\begin{array}{llllll}\text { MZ } & 13 / 5 / 99 & 102.0 & 13 / 3 / 11 & 106.1 & 2\end{array}$

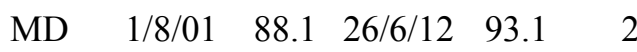

$\begin{array}{llllll}\text { MD } & 4 / 8 / 94 & 98.5 & 7 / 8 / 01 & 98.9 & 2\end{array}$

$\begin{array}{llllll}\text { MD } & 14 / 7 / 95 & 104.0 & 25 / 6 / 12 & 104.8 & 3\end{array}$

$\begin{array}{llllll}\text { MD } & 14 / 7 / 89 & 107.5 & 6 / 7 / 07 & 107.4 & 5\end{array}$

$\begin{array}{lllll}\text { CL } & 11 / 7 / 88 & 108.5 & 14 / 6 / 91 & 108.5\end{array}$

$\begin{array}{ccccc}15.5 & 6 & \text { HI } & 2 & <10 \\ 15.7 & 7 & \text { HI } & 1 & <10 \\ 15.3 & 7 & \text { HI } & 1 & <10 \\ 13.1 & 4 & \text { HI } & 1 & <10 \\ 4 & 4 & \text { HI } & 1 & <10 \\ 11.6 & 4 & \text { HI } & 2 & <10 \\ 11.4 & 6 & \text { HI } & 1 & <10 \\ 8.6 & 6 & \text { HI } & 1 & <10 \\ 8.4 & 6 & \text { HI } & 1 & <10 \\ 7.6 & 8 & \text { HI } & 1 & <10 \\ 3.6 & <1 & \text { HI } & 1 & <10 \\ 5.4 & 6 & \text { HI } & 1 & <10 \\ 9 & 1 & \text { FR } & 1 & 438 \\ 7 & <1 & \text { NW } & 1 & 26 \\ 11.9 & <1 & \text { HI } & 1 & <10 \\ 10.7 & <1 & \text { HI } & 1 & <10 \\ 19.6 & 7 & \text { HI } & 2 & <10 \\ 14 & 5 & \text { HI } & 4 & <10 \\ 17.8 & 5 & \text { HI } & 2 & <10 \\ 8.4 & <1 & \text { HI } & 1 & <10 \\ 3.3 & <1 & \text { RI } & 1 & <10 \\ 11.8 & 1 & \text { NC } & 1 & 1428 \\ 10.9 & 1 & \text { N2 } & 1 & 1412 \\ 7 & 3 & \text { NC } & 1 & 1605 \\ 17 & 1 & \text { NC } & 1 & 1610 \\ 18 & 7 & \text { HZ } & 1 & 614 \\ 2.9 & <1 & \text { NW,WI } & 1 & 1308\end{array}$

Loggerhead turtle (Caretta caretta)

\begin{tabular}{|c|c|c|c|c|c|c|c|c|c|c|c|c|c|}
\hline $2912^{c}$ & $\mathrm{sPac}$ & $\mathrm{F}$ & HI & $3 / 11 / 74$ & & $31 / 3 / 92$ & & 38 & 17.4 & $<1$ & MR & 1 & 159 \\
\hline $5330^{c}$ & $\mathrm{sPac}$ & $\mathrm{F}$ & WT & $14 / 5 / 75$ & & 25/3/92 & 94.5 & 4 & 16.9 & $<1$ & $\mathrm{BA}, \mathrm{KM}, \mathrm{MR}$ & 6 & 159 \\
\hline $10779^{c}$ & $\mathrm{sPac}$ & F & HI,WT & $12 / 5 / 75$ & 92.5 & $19 / 10 / 95$ & & 14 & 20.5 & 8 & KM,MR & 4 & 163 \\
\hline K25843 & $\mathrm{sPac}$ & $\mathrm{F}$ & MZ & $10 / 5 / 99$ & 88.9 & $8 / 4 / 05$ & 89.5 & 3 & 5.9 & 4 & MR & 1 & 299 \\
\hline K40329 & $\mathrm{sPac}$ & $\mathrm{F}$ & MZ & $5 / 6 / 02$ & 92.2 & $22 / 9 / 06$ & 94.6 & 2 & 4.3 & 6 & MR & 1 & 300 \\
\hline K55341 & $\mathrm{sPac}$ & $\mathrm{F}$ & S\$ & $6 / 10 / 06$ & & $24 / 4 / 10$ & & 6 & 3.6 & 7 & MR & 1 & 138 \\
\hline $\mathrm{T} 732^{\mathrm{e}}$ & $\mathrm{sPac}$ & $\mathrm{F}$ & $\mathrm{HI}$ & $17 / 10 / 82$ & 78.5 & $2 / 11 / 99$ & & 32 & 17.1 & 7 & MR & 2 & 161 \\
\hline T2429a & sPac & $\mathrm{F}$ & MO,MZ & $26 / 4 / 92$ & 95.5 & $10 / 10 / 95$ & 96.0 & 2 & 3.5 & 20 & MR & 1 & 299 \\
\hline $\mathrm{T} 22667^{\mathrm{a}}$ & $\mathrm{sPac}$ & $\mathrm{F}$ & $\mathrm{MZ}$ & 10/6/91 & 101.5 & $13 / 8 / 95$ & 100.7 & 2 & 4.2 & 3 & WR & 1 & 365 \\
\hline T22706a & $\mathrm{sPac}$ & $\mathrm{F}$ & MZ & 2/9/90 & 96.2 & $25 / 5 / 04$ & 97.3 & 7 & 13.7 & 6 & WR & 1 & 369 \\
\hline T23637a & $\mathrm{sPac}$ & $\mathrm{F}$ & MZ & $25 / 5 / 91$ & 88.0 & 29/5/97 & 88.8 & 2 & 6 & 4 & MR & 1 & 298 \\
\hline T38229e & $\mathrm{sPac}$ & $\mathrm{F}$ & HI & $16 / 4 / 89$ & 77.0 & $26 / 10 / 99$ & 100.5 & 19 & 10.5 & 5 & $\mathrm{RB}$ & 1 & 115 \\
\hline T41196 & $\mathrm{sPac}$ & $\mathrm{F}$ & MZ & $16 / 9 / 90$ & 86.3 & $30 / 5 / 06$ & 87.0 & 3 & 15.7 & 4 & MR & 3 & 301 \\
\hline Т50968 & $\mathrm{sPac}$ & $\mathrm{F}$ & MZ & $1 / 9 / 90$ & 90.5 & $15 / 7 / 18$ & 91.3 & 14 & 27.9 & 5 & MR & 2 & 301 \\
\hline T64304 & $\mathrm{sPac}$ & $\mathrm{F}$ & MZ & 9/5/92 & 90.8 & $17 / 9 / 17$ & 90.2 & 7 & 25.4 & 5 & MO & 1 & 21 \\
\hline T85935 & $\mathrm{sPac}$ & $\mathrm{F}$ & QG & $5 / 5 / 01$ & & $12 / 7 / 08$ & & 2 & 7.2 & 14 & WI & 1 & 555 \\
\hline T93076 & $\mathrm{sPac}$ & $\mathrm{F}$ & MZ & $19 / 4 / 97$ & 82.9 & $13 / 9 / 15$ & 89.0 & 6 & 18.4 & 5 & MR & 2 & 304 \\
\hline $\mathrm{X} 54^{\mathrm{c}}$ & $\mathrm{sPac}$ & $\mathrm{F}$ & HI,WT & $7 / 11 / 75$ & 100.5 & $23 / 10 / 85$ & & 33 & 10 & 7 & MR & 2 & 159 \\
\hline X198 & $\mathrm{sPac}$ & $\mathrm{F}$ & HI,WT & $13 / 5 / 75$ & 92.5 & 22/8/99 & 95.4 & 14 & 24.3 & 11 & MR & 4 & 161 \\
\hline $\mathrm{X} 2031^{\mathrm{c}}$ & $\mathrm{sPac}$ & $\mathrm{F}$ & HI & $12 / 5 / 75$ & 101.0 & $1 / 11 / 99$ & & 51 & 24.5 & 7 & HI,SH,SP & 2 & 205 \\
\hline$X 2061^{d}$ & sPac & $\mathrm{F}$ & $\mathrm{HI}$ & $13 / 5 / 75$ & 83.0 & $23 / 10 / 85$ & 86.0 & 9 & 10.5 & $<1$ & WI & 1 & 12 \\
\hline$X 2352^{c}$ & $\mathrm{sPac}$ & $\mathrm{F}$ & HI,WT & $6 / 5 / 76$ & 92.0 & 2/4/92 & 94.2 & 10 & 15.9 & 7 & WR & 3 & 98 \\
\hline $\mathrm{X} 2606^{\mathrm{c}}$ & $\mathrm{sPac}$ & $\mathrm{F}$ & HI & $10 / 5 / 76$ & 87.0 & $12 / 5 / 84$ & & 23 & 8 & $<1$ & MR & 1 & 159 \\
\hline$X 2757^{e}$ & $\mathrm{sPac}$ & $\mathrm{F}$ & HI & $19 / 5 / 77$ & 80.0 & $6 / 11 / 96$ & & 47 & 19.5 & 5 & LM & 3 & 70 \\
\hline X2776 & $\mathrm{sPac}$ & $\mathrm{F}$ & HI,WT & $23 / 5 / 77$ & 90.0 & $31 / 7 / 98$ & 93.7 & 14 & 21.2 & 10 & WR & 4 & 98 \\
\hline $\mathrm{X} 2777^{\mathrm{c}}$ & sPac & $\mathrm{F}$ & WT & $23 / 5 / 77$ & 89.5 & $30 / 8 / 85$ & 92.0 & 5 & 8.3 & $<1$ & WR & 2 & 93 \\
\hline X9334e & $\mathrm{sPac}$ & $\mathrm{F}$ & $\mathrm{HI}$ & $4 / 11 / 77$ & & $24 / 10 / 98$ & 99.1 & 42 & 21 & 5 & $\mathrm{NC}$ & 1 & 1590 \\
\hline X9342 & sPac & $\mathrm{F}$ & HI,WT & $5 / 11 / 77$ & 99.0 & $26 / 10 / 97$ & 101.0 & 9 & 20 & 7 & WI & 1 & 18 \\
\hline X9343 & $\mathrm{sPac}$ & $\mathrm{F}$ & HI,WT & $5 / 11 / 77$ & 82.5 & 29/10/99 & 92.3 & 12 & 22 & 7 & SF & 1 & 197 \\
\hline X9374e & $\mathrm{sPac}$ & $\mathrm{F}$ & HI & $6 / 2 / 78$ & 86.0 & $1 / 11 / 95$ & 97.0 & 27 & 17.7 & 4 & WR & 1 & 98 \\
\hline X44080 & $\mathrm{sPac}$ & $\mathrm{F}$ & MB & $24 / 9 / 84$ & & $17 / 3 / 95$ & & 2 & 10.5 & 16 & WI & 3 & 461 \\
\hline X44635 & $\mathrm{sPac}$ & $\mathrm{F}$ & MZ & $31 / 8 / 91$ & 93.5 & $28 / 2 / 10$ & 93.1 & 4 & 18.5 & 7 & WI & 1 & 473 \\
\hline T708 & $\mathrm{sPac}$ & M & HI & $15 / 10 / 82$ & 80.0 & $12 / 4 / 10$ & & 24 & 27.5 & 5 & $\mathrm{HI}$ & 2 & $<10$ \\
\hline X2034 & $\mathrm{sPac}$ & M & $\mathrm{HI}$ & $12 / 5 / 75$ & 99.5 & 19/8/99 & 101.0 & 21 & 24.3 & 7 & $\mathrm{HI}$ & 1 & $<10$ \\
\hline X2073 & sPac & M & HI,WT & $13 / 5 / 75$ & 94.5 & $5 / 1 / 86$ & 96.0 & 20 & 10.7 & 7 & $\mathrm{HI}$ & 1 & $<10$ \\
\hline
\end{tabular}




\begin{tabular}{|c|c|c|c|c|c|c|c|c|c|c|c|c|}
\hline $\mathrm{X} 2210$ & sPac & M & HI & $30 / 10 / 75$ & 94.0 & $11 / 8 / 98$ & 50 & 22.8 & 6 & $\mathrm{HI}$ & 2 & $<10$ \\
\hline X2298 & $\mathrm{sPac}$ & M & HI & $17 / 12 / 75$ & & $7 / 11 / 82$ & 8 & 6.9 & $<1$ & $\mathrm{HI}$ & 1 & $<10$ \\
\hline X2531 & sPac & M & HI & $17 / 2 / 78$ & 95.5 & $26 / 9 / 85$ & 27 & 7.6 & $<1$ & $\mathrm{HI}$ & 1 & $<10$ \\
\hline X2615 & $\mathrm{sPac}$ & M & $\mathrm{HI}$ & $10 / 5 / 76$ & 94.5 & $18 / 3 / 86$ & 21 & 9.9 & $<1$ & $\mathrm{HI}$ & 1 & $<10$ \\
\hline
\end{tabular}

Flatback turtle (Natator depressus)

$\begin{array}{llllll}\text { X35035 eAus F MK } 31 / 7 / 91 & 2 & \text { PI } & 1+ & 286\end{array}$

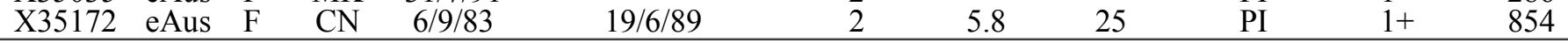

${ }^{\#}$ This turtle was originally recorded in 1975 as a hatchling at its natal beach in Mon Repos, Queensland, Australia. See main text for details.

${ }^{a}$ Limpus \& Limpus (2001); ${ }^{c}$ Limpus (1989); ${ }^{\mathrm{d}}$ Limpus et al. (1992); ${ }^{\mathrm{e}}$ Limpus \& Limpus (2003); ${ }^{\mathrm{f}}$ Limpus et al. (2005);

${ }^{g}$ Read et al. (2014)

\section{References}

Limpus, C. J. (1989). Forage area fidelity following breeding migrations in Caretta caretta. In S. A. Eckert, K. L. Eckert, \& T. H. Richardson (Eds.), Proceedings of the ninth annual workshop on sea turtle conservation and ecology (pp. 97-99). Jekyll Island, Georgia: NOAA Technical Memorandum NMFS-SEFC-232.

Limpus, C. J., Deacon, M., \& Meech, J. (1993). Dead turtles on the Woongarra Marine Park and adjacent coast (pp. 1-15). Brisbane: Queensland Department of Environment and Heritage.

Limpus, C. J., \& Limpus, D. J. (2001). The loggerhead turtle, Caretta caretta, in Queensland: breeding migrations and fidelity to a warm temperate feeding area. Chelonian Conservation and Biology, 4(1), $142-153$.

Limpus, C. J., \& Limpus, D. J. (2003). Biology of the loggerhead turtle in western south Pacific Ocean foraging areas. In A. B. Bolten \& B. E. Witherington (Eds.), Loggerhead sea turtles (pp. 93-113). Washington, DC: Smithsonian Books.

Limpus, C. J., Limpus, D. J., Arthur, K. E., \& Parmenter, C. J. (2005). Monitoring green turtle population dynamics in Shoalwater Bay: 2000 - 2004. Great Barrier Reef Marine Park Authority Research Publication, 83, i-v, 1-51.

Limpus, C. J., Miller, J. D., Parmenter, C. J., Reimer, D., Mclachlan, N., \& Webb, R. (1992). Migration of green (Chelonia mydas) and loggerhead (Caretta caretta) turtles to and from eastern Australian rookeries. Wildlife Research, 19(3), 347-358. doi: 10.1071/WR9920347

Queensland Department of Environment and Science. (2018). Marine Wildlife Stranding Database (StrandNet).

Queensland Environmental Protection Agency. (2018). Queensland Turtle Conservation Project database.

Read, T. C., Wantiez, L., Werry, J. M., Farman, R., Petro, G., \& Limpus, C. J. (2014). Migrations of green turtles (Chelonia mydas) between nesting and goraging grounds across the Coral Sea. PloS One, 9(6), e100083-e100083. doi: 10.1371/journal.pone.0100083 
Wildermann, N. (2017). Flatbacks at sea: understanding ecology in foraging populations ( $\mathrm{PhD}$ thesis). James Cook University, Townsville. 